\title{
Team Dynamics Theory: Nomological network among cohesion, team mental models, coordination, and collective efficacy
}

\author{
Edson Filho ${ }^{1}$ (D)
}

Received: 10 July 2018 / Accepted: 2 December 2018 / Published online: 29 December 2018

(c) The Author(s) 2018

\begin{abstract}
I put forth a theoretical framework, namely Team Dynamics Theory (TDT), to address the need for a parsimonious yet integrated, explanatory and systemic view of team dynamics. In TDT, I integrate team processes and outputs and explain their relationships within a systemic view of team dynamics. Specifically, I propose a generative nomological network linking cohesion, team mental models, coordination, collective efficacy, and team outcomes. From this nomological conceptualization, I illustrate how myriad alternative models can be derived to account for variance in different working teams, each comprised of unique members, and embedded in singular contexts. I outline TDT's applied implications for team development, the enhancement of team functioning, and the profiling of team resilience. I conclude by discussing how TDT's ontological and nomological propositions can be tested through various theoretical inquiries, methodological approaches, and intervention-based studies.
\end{abstract}

Keywords Cohesion $\cdot$ Team mental models $\cdot$ Coordination $\cdot$ Collective efficacy $\cdot$ Team outcomes

\section{Introduction}

The importance of teams in society and the natural world is ubiquitous. Working as a team allows individual members to take on sub-tasks to achieve highly complex goals that cannot be achieved by individuals working alone. In the Sport, Exercise, and Performance Psychology literature, previous attempts have been made to link different team processes within a coherent framework of team dynamics. In this study I discuss these attempts and outline a new theoretical framework, which I call Team Dynamics Theory (TDT). In what follows is an attempt to address "the demarcation problem" which Popper [1] says all theoretical proposals must face. I begin by outlining the goals and delimiting the scope of TDT. I then elaborate on the themes and sub-themes of the theory, review the most relevant models anteceding TDT, and explain the ontological and nomological assumptions and propositions of the theory. I discuss applied implications

Edson Filho

efilho@uclan.ac.uk

1 Social Interaction and Performance Science (SINAPSE) Lab, School of Psychology, University of Central Lancashire, Darwin Building 114, Preston PR1 2HE, UK of TDT and conclude by proposing avenues for future research.

\section{Goals of TDT}

Many applied psychologists have acknowledged the need for an integrated, systemic, and explanatory theory of team dynamics. For example, Bandura [2-4] discussed the importance of testing for "reciprocal determinism" between collective efficacy and myriad social cognitive variables. Carron et al. highlighted the need for developing a framework to integrate cohesion with other team processes and outcomes [5-8]. Other scholars have emphasized the need to clarify the nomological roots of team mental models [9-18].

The importance of examining the linkage between coordination and other team attributes has also been emphasized in the applied psychology literature [19-30]. Recently, several scholars have called for an integrated framework of team dynamics to advance not only theory on this matter but also to offer practitioners guidance on how to develop highperforming teams [31-39]. In this context, the overarching goal of TDT is to provide an integrated, explanatory, and systemic framework to study team dynamics across domains of human interest. 


\section{Towards an integrated explanatory theory of team dynamics}

TDT integrates four team processes with respect to an output: cohesion (CO), team mental models (TMM), coordination (CD), collective efficacy (CE), and team outcomes (TO). Theoretical integration among existing concepts is important to minimize what has been called the "toothbrush problem" in psychology. As Watkins [40] observed, "psychologists treat other people's theories like toothbrushes-no self-respecting person wants to use anyone else's" (p. 86). Put plainly, TDT stems from previous theoretical and empirical work in applied psychology, particularly literature in the field of Sport, Exercise, and Performance Psychology, wherein scholars and practitioners have tried to describe and explain team dynamics in relation to performance [41, 42].

TDT is not a descriptive theory but rather an explanatory theory $[43,44]$. Thus, rather than trying to describe all existing team processes, TDT aims to explain part of team dynamics variability and predict TO using four inputs: CO, TMM, CD, and CE. To further illustrate the distinction between descriptive and explanatory models, some scholars in chemistry and physics have focused on describing what the elements in the periodic table are, while others have tried to explain how and why the linkages among certain elements take place in the natural world. Overall, explanatory theories lean towards a systemic approach $[45,46]$.

\section{Towards a systemic theory of team dynamics}

To deal with complexities, one can adopt a holistic or systemic focus [46, 47]. Holistic theories try to explain everything or summarize an entire set of rules into a single overarching rule. For instance, we know that physiologists try to identify thresholds (e.g., lactate; maximum heart rate) that apply to all individuals, and physicists are currently trying to develop a "theory of everything" by reconciling mechanics and quantum physics principles. TDT is not a holistic theory, as it does not attempt to encompass all team processes and nuances of team dynamics, but instead is a systemic theory. In other words, accounting for all team processes and sub-processes is beyond the remit of TDT.

In systemic theories, the goal is not to find a single overarching rule but rather to explain relations among a specific set of variables. I theorize on the linkage among $\mathrm{CO}, \mathrm{TMM}, \mathrm{CD}, \mathrm{CE}$, and TO, and take inspiration from meta-theorists in both the social sciences and natural sciences who were also interested in "means and ends" systemic relations among variables. In his theory of syntax, Chomsky [43] noted that fluency in a language is not about knowing all words that exist but rather learning how words are connected in a systemic fashion. In the natural sciences, biologists have not catalogued all existing living species, but they have evolved the notion of an eco-system on how living organisms and the physical environment are intertwined [48, 49]. Overall, systemic theories focus on the relationship among a set of variables within a welldefined scope $[45,46]$.

\section{Theoretical scope}

In TDT, the team is the locus of analysis, and thus the focus and measurement approach is at the inter-relationship between individuals. Teams differ from groups insofar that individuals in a team are united by shared goals, whereas individuals in a group are not [41]. CO, TMM, CD, and $\mathrm{CE}$ are processes at the team-level of analysis and represent team ("we" and "us") rather than individual ("I" and "me") factors [50-52]. That is, CO, TMM, CD, and CE emerge from the team as a whole rather than from any single individual, akin to the gestalt notion that "the whole is greater than the sum of its parts". For instance, an individual may not feel a strong bond to his/her team or have clear coordination roles within his/her team, but CO, TMM, and CD might still be high within the team as a whole. The same rationale applies to CE and other team processes. An individual might feel highly confident in him/herself but still perceive the team as lacking CE. Moreover, an individual may perform at a high level and the team as a whole may underperform or, alternatively, an individual may perform poorly but the overall team performance is good.

Though the locus of analysis is the team, it is important to note that "we" and "us" processes influence and are influenced by "I" and "me" factors, as well as by myriad contextual constraints [51, 53] (Fig. 1). Accordingly, individual and contextual factors should be controlled for in studies examining team processes. Theorizing about all possible individual and contextual factors that may moderate the CO-TMM-CDCE linkage would be an endless task, perhaps creating what some call "the infinite regression problem" in epistemology [54] and is beyond the scope of this proposal. The individual and contextual factors to control for in a given study are at the discretion of the researcher and will depend on the questions proposed.

The role of leadership also merits consideration, as leadership is one of the most important concepts in team dynamics research and practice. Notwithstanding, I argue that the effects of leadership on the CO-TMM-CD-CE-TO linkage should be tested separately. There are several different approaches to leadership, including trait, behavioral, 


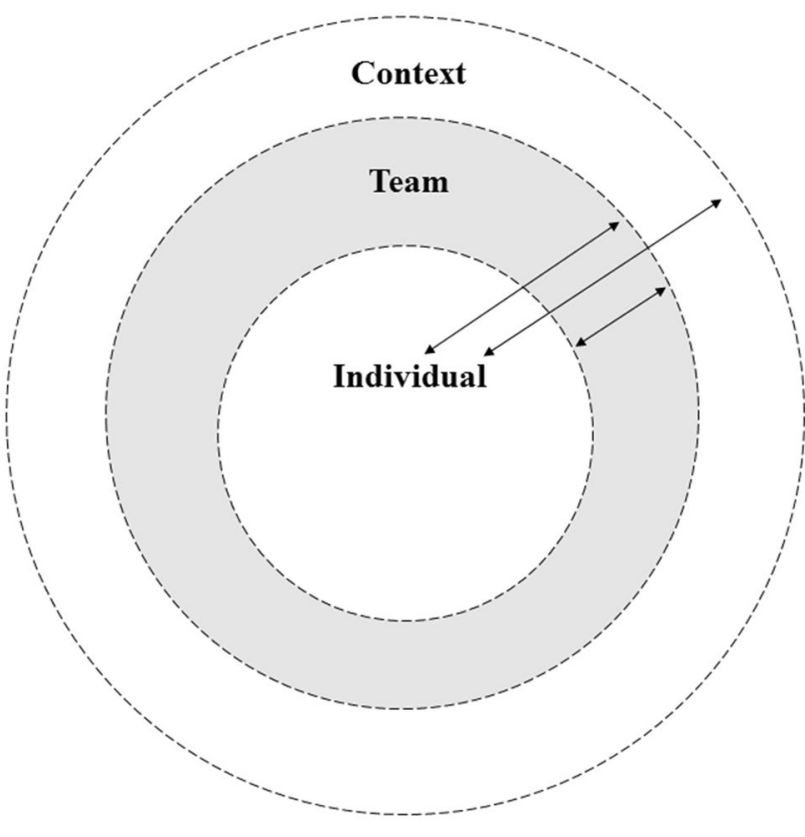

Fig. 1 TDT focuses on emergent team processes, which influence and are influenced by individual and contextual factors

transactional, transformational, and strategic [55], and the reflective latent indicators (or sub-themes) and unit of analysis for each of these approaches varies greatly [56-58]. Perhaps more importantly, in all of these approaches, the unit of analysis varies within the leader-follower dichotomy
[59]. While some scholars argue that leadership is an "I" factor as it stems from the characteristics of the individual, others argue that leadership is "in the eye of the beholder" because it is the group of followers that seek identification with the leader $[60,61]$. It follows that the unit of analysis in which leadership should be measured, as well as the functions of various leaders with the team, remains an ongoing debate [62, 63]. Given that TDT is conceptualized at the team-level, I contend that the specific effects of different leadership approaches on team dynamics should be tested and accounted for according to the specific aims of the researcher.

\section{Themes and sub-themes}

In developing TDT I abide by the principle of parsimony. Themes and sub-themes are thought to represent unique factorial contributions to the study of team dynamics. Therefore, I discuss the putative, most relevant, themes and subthemes only. I first discuss CO, then present TMM and CD together as they are inherently connected, and subsequently elaborate on CE and TO.

\section{Cohesion}

Many definitions of $\mathrm{CO}$ have been provided in the literature [64], all of which refer to the idea that individuals come and

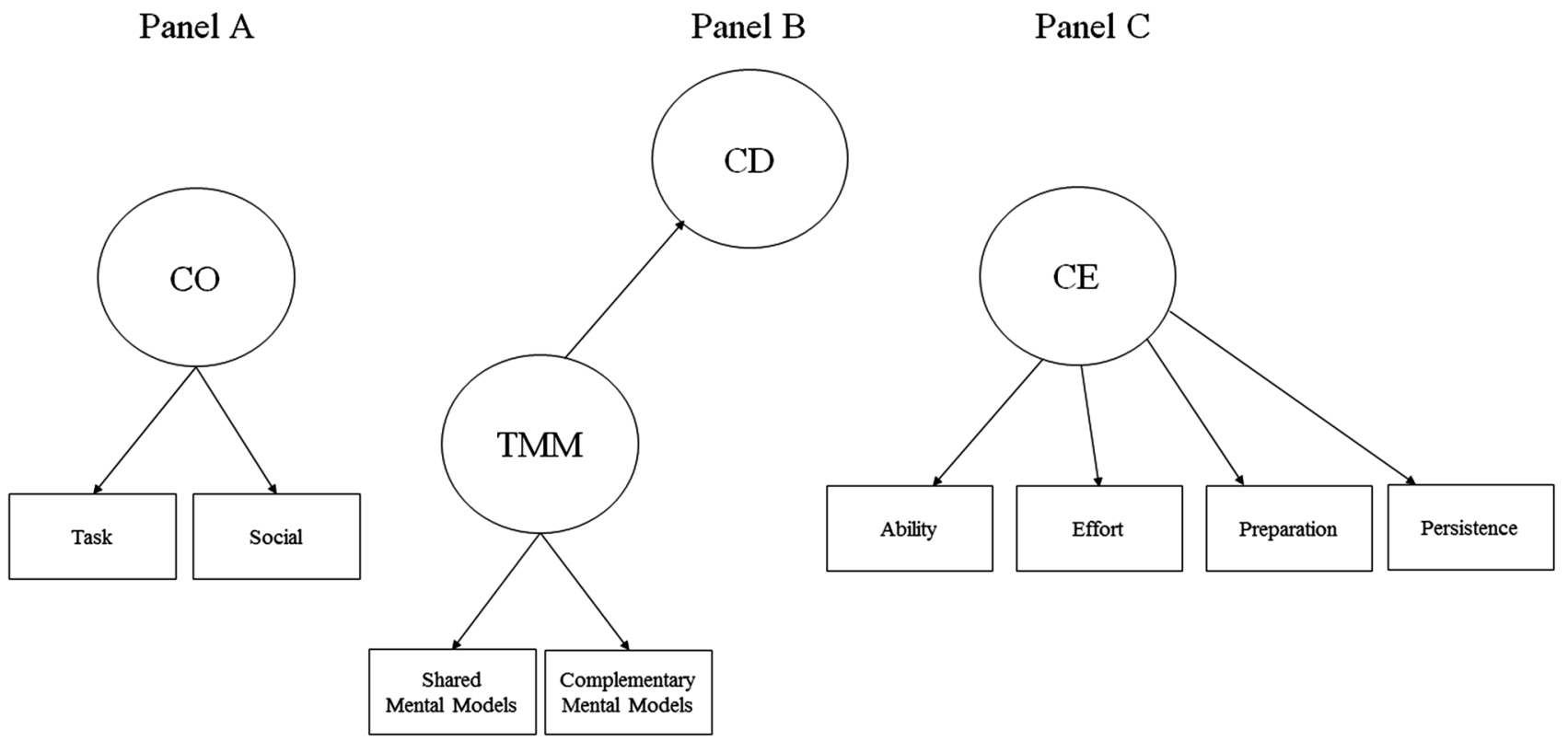

Fig. 2 Proposed themes and sub-themes in TDT. Task Cohesion and Social Cohesion are conceptualized as reflective indicators of Cohesion (CO; see a). Shared Mental Models and Complementary Mental Models are conceptualized as reflective indicators of Team Mental
Models (TMM), which in turn is conceptualized as a formative indicator of Coordination (CD; see b). Ability, effort, preparation, and persistence are conceptualized as reflective indicators of Collective Efficacy (CE; c) 
stay together to pursue task or social interdependent goals (Fig. 2a). In effect, the lexical roots of the word cohesion reveal its literal meaning: co denotes "jointly or mutually", while haerere means "stick" [65, p. 59]. Therefore, cohesion pertains to the social and task forces that bring and keep individuals together [64, 66, 67]. Importantly, social and task cohesion have been conceptualized as orthogonal to one another [68, 69]. For instance, a team may be very high in task cohesion and very low in social cohesion or vice-versa, and all variations in between apply as well (e.g., low social cohesion and low task cohesion).

Although social cohesion is highly desirable as we are inherently social beings with needs to belong and feel loved [70], task cohesion is thought to be more central to the formation and maintenance of working teams [64, 65]. Evolutionary biologists and psychologists defend the notion that animals unite and remain together primarily to achieve task goals, such as hunting in wolf packs and food gathering among social insects [71, 72]. On this matter, Carron and Brawley [73] pinpointed that "Cohesion has an instrumental basis. All groups-musical groups, work groups, sport groups, committee, form for a purpose. Even groups that may be considered purely "social" in nature have an instrumental basis for their formation" (p. 95). Once individuals have established communal goals they are, by definition, a "team" and other team processes, such as team mental models and coordination patterns, can develop.

\section{Team mental models and coordination}

Different terminologies have been used to denote research on team cognition, including "team mind", "transactive memory systems", and "shared mental models" [74]. TMM, however, has been proposed as a comprehensive terminology to represent research on this theme $[14,75]$. The inclusion of "team" in TMM makes it clear that the unit of analysis is at the team-level [14]. Furthermore, TMM is sufficiently broad and encompasses both the shared/communal and complementary/idiosyncratic knowledge properties held by teammates [75]. To this extent, recent studies on hyperbrains offer empirical support for the notion of TMM, suggesting that one brain is the fractal of two brains, which in turn are the fractal of three brains, and so forth [76-78]. More precisely, individuals engaged in interactive tasks (e.g., airplane flying, cooperative juggling, duet guitar playing) depend on shared and complementary neural activity to successfully coordinate their actions [76, 79-82]. That is, individuals activate shared/communal as well as complementary/idiosyncratic functional networks during the execution of interactive team tasks. In practice, without shared knowledge, team members are unable to anticipate each other's actions or develop heuristic action plans [9, 10, 38, 83-87]. Without complementary mental models, team members cannot compensate for each other's mistakes or execute highly complex team tasks requiring different knowledge backgrounds, distributed effort, and empathy [76, 88-90].

Accordingly, I define TMM as the extent (quantity) and accuracy (quality) of shared and complementary cognitive-affective-behavioral knowledge types (know-what; know-why; know-where; know-when; know-how) held by team members about the individuals in the team, team tasks, the team as a whole, and contextual constraints. This definition is broadly conceived in an attempt to express that TMM are (1) of varying magnitudes and accuracy; (2) inter-related cognitive, affective and behavioral states and patterns; (3) expressed through different knowledge types, including descriptive, micro-tactical and macrostrategic, procedural, and temporal; and (4) a cross-level property related to individuals, tasks, the team, and contextual information.

Importantly, communication, via verbal, non-verbal, and other language mediums (e.g., electronic), is conceptualized as part of TMM. There is consensus that TMM are revealed through explicit and implicit communication exchanges [14, 91]. Moreover, previous research suggests that communication dynamics change as TMM develop over time [92, 93]. From a nature standpoint, language is a genetically endowed mechanism geared at allowing individuals to communicate shared and complementary cognitive-affective-behavioral information [43]. From a nurture standpoint, language is acquired knowledge and varies among working teams. If an individual is not part of a team, s/he may not have the language (from langue, meaning an abstract system of knowledge used by a collection of individuals) of shared and complementary schemas needed to communicate effectively within that team [94-96]. For instance, military units and sport teams have unique communication jargon and non-verbal signals, only known to their respective members $[96,97]$.

Shared and complementary mental models represent reflective indicators of TMM, which in turn operate as formative indicators of CD (Fig. 2b). To go back one step, higher themes can be represented by reflective or formative indicators, as detailed elsewhere [98, 99]. TMM and CD are intertwined constructs given that $\mathrm{CD}$ cannot occur without shared and complementary properties $[27,29,30,38$, 100-103]. To be "at the right place, at the right time, doing the right thing", teammates need to know "who does what, why, where, when, and how". In fact, whether the unit of analysis is an atom, a muscle group, or a sports team, coordination is possible through the synchronization of shared and complementary attributes, such as positive and negative charges in an atom, agonist and antagonist fibers in a muscle group, and the division of communal and idiosyncratic responsibilities in a sports team. Noteworthy, the efficacy beliefs teammates hold about their team's ability to succeed is also paramount in team dynamics, as detailed next. 


\section{Collective efficacy}

Bandura defined CE as "a group's shared belief in its conjoint capabilities to organize and execute the courses of action required to produce given levels of attainment" [4, p. 4]. While other definitions of $\mathrm{CE}$ are available in the literature [104, p. 817], Bandura's [4] definition remains the most popular among applied psychologists [5] and is adopted herein. Relevant to TDT, this definition makes it clear that CE is operationalized at the group level of analysis, and is therefore a "we" belief [105].

$\mathrm{CE}$ and self-efficacy are thought to have "similar sources, serve similar functions, and operate through similar processes" [4, p. 478]. Notwithstanding, unique sources of CE exist in theory and have been described previously in the literature [106-108]. In TDT, CE is thought to be reflective of the individuals' confidence level in their team's ability, effort, preparation, and persistence (Fig. 2c), mirroring the sub-factors put forth by Short, Sullivan, and Feltz [109]. Of note, "unity", which is also described by Short et al. [109] as a reflective indicator of $\mathrm{CE}$, overlaps with the operational definition of $\mathrm{CO}$ and is thus not considered further [90], as TDT aims for parsimony.

Short et al. work [109] is relevant in developing an integrative framework of team dynamics as it abided by Bandura's [110] recommendation for developing efficacy measures. Furthermore, their work has informed research on CE in interactive teams in Sport, Exercise and Performance Psychology over the past decade. In principle, the greater the ability of the team as a whole, the higher the expectation of success [111]. The notion that greater preparation and effort are positively linked to efficacy beliefs is both theoretically sound and empirically valid [112]. The mechanism is straightforward: preparation and effort decrease anxiety and increase confidence [113]. Persistence reflects confidence, as team success often requires long-term commitment, and more confident teams will show greater persistence [114]. Altogether, the greater the $\mathrm{CE}$, the higher the probability of positive TO.

\section{Team outcomes}

TO vary greatly depending on the working teams domain or area of interest, as TO for sport, military, civil aviation, medical, and industrial teams differ. Among applied psychologists, measures of performance, satisfaction, and well-being are among the most commonly studied outcomes across team settings $[42,115]$. Broadly conceived, scholars and practitioners are often interested in whether a team is performing well (e.g., number of wins over the season for a sports team; number of on-time arrivals in civil aviation), feeling satisfied or making others happy (e.g., job satisfaction; customer satisfaction), and keeping healthy (e.g., burnout rates; absent days). Delimiting all TO is an infinite task and is beyond the scope of this proposal. In general terms, TO can be derived by assessing the goals appropriate to a given domain in general or a given team in particular [116-118]. Consequently, it is important to consider both objective and subjective measures of TO.

Objective measures of TO are less affected by measurement error and subjective methodological biases [119], and thus provide more reliable data about team performance, satisfaction, and well-being. However, subjective scores may better represent individuals' "we" beliefs and assessments of TO [120]. For instance, purely objective scores do not account for an outstanding performance from an opposing team, judging mistakes, and other contextual factors (e.g., bad weather in civil aviation or sports; economic recession in business). Outcome scores also depend on who is judging, as team leaders, team members, and external judges may differ in their interpretation of what constitutes an optimal output [121]. Altogether, the assessment of both objective and subjective measures has been part of previous empirical research examining the relationship among TO and team processes in applied psychology.

The linkage among TO and the team processes discussed herein has been observed in studies on teams from various domains. Overall, $\mathrm{CO}$ and TO have been found to be reciprocally linked [122-125]. TMM and CD have also been found to be associated with TO [12, 13, 91, 93, 126-135]. Likewise, $\mathrm{CE}$ has been found to be positively associated with TO [136-140].

Previous empirical research has also examined the relationships among the team processes integrated in TDT, with some relationships being more extensively studied than others. CO has been found to be positively linked to TMM [33, 141], as well as CE [142-147]. Furthermore, TMM and CD have been found to co-vary with CE beliefs [35, 148-150]. Notwithstanding, existing research has been informed by numerous frameworks, thereby making empirical reproducibility and theoretical integration problematic. On this note, it is important to reiterate that TDT was not conceptualized in a vacuum nor did it arise from a eureka moment. Rather, TDT derives from previous theoretical grounds, particularly frameworks in the Sport, Exercise and Performance Psychology domain.

\section{Theoretical roots}

The themes discussed herein have their own theoretical roots: TMM is tied to Theory of Mind [151], CE is derived in part from Social Learning Theory [152, 153], and CD stems from theoretical streams in both the natural and social sciences [154]. Importantly, however, the idea of relating various team processes within the same nomological 
network, which is the goal of TDT, can be traced back to McGrath' [155] input-process-output model. Within the Sport, Exercise and Performance Psychology, TDT stems primarily from the attempts of Carron and associates to account for the antecedents, correlates, and outcomes of CO. Thus, next I briefly discuss how previous frameworks in Sport, Exercise and Performance Psychology literature have informed the development of TDT and provide an interpretative phenomenological scheme of TDT's roots (Fig. 3).

\section{Conceptual system for cohesiveness in sport teams}

Carron [156] was one of the earliest scholars to discuss input-output relations in group and team processes, at least in the field we now call Sport, Exercise and Performance Psychology. At the time, Carron was mostly concerned with cohesion in sport and industrial settings. He proposed that environmental factors were exogenous to personal factors and leadership factors, and that these three factors influenced team factors, which subsequently influenced cohesion, which then impacted individual outcomes and group outcomes. Carron proposed that these higher-order themes were underpinned by 24 different constructs. Unlike TDT, Carron's seminal model was descriptive rather than explanatory in nature, did not explicitly differentiate groups from teams, and did not discuss other higher-order team processes, such as $\mathrm{CD}$ and $\mathrm{CE}$.

Carron later stated that his original model was developed to "help investigators systematically organize the research pertaining to cohesion" [157, p. 226] and was not "intended to be a definitive view of the elements that cause cohesion and/or result from cohesion-although it was interpreted that way by a number of authors" [158, p. 242]. Carron's model generated important empirical work that in turn led to the development of other conceptual frameworks, including the Conceptual Model of Group Cohesion for Sport (1985), which remains the leading framework for studying cohesion in the field of Sport, Exercise and Performance Psychology. Additionally, Carron's [5] seminal proposal was later modified to address the relationship between team cohesion and other team processes, which eventually led to the development of the Conceptual Framework of Team Building.

\section{Conceptual framework of team building}

Carron and Spink [7] advanced a Conceptual Framework of Team Building by discussing input-throughput-output relations among a set of higher-order factors underpinned by sub-factors. Different from TDT, this framework focused on groups rather than teams and subscribed to a linear view of group dynamics. Specifically, Carron and Spink formulated that two throughput group processes (i.e., interaction

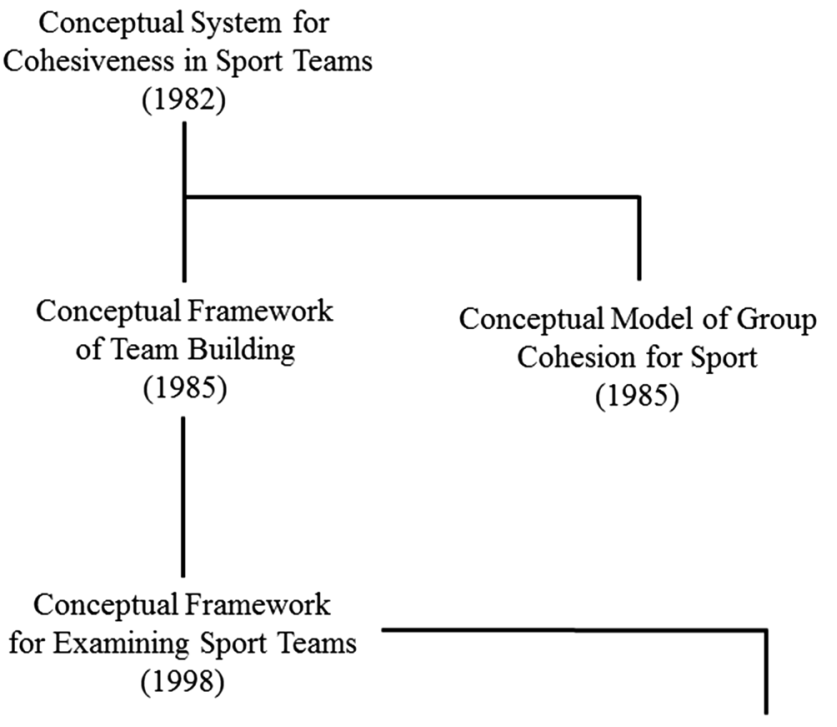

Integrated Framework of Team

Dynamics in Sports

(2015)

Team Dynamics

Theory

Fig. 3 Schematic tree of TDT's theoretical roots. TDT descends from previous models in Sport, Exercise and Performance Psychology geared towards explaining input-throughout-output relations among team processes and outcomes 
and communication and sacrifices) mediated the relationship between two inputs (i.e., group environment and group structure) and the output group cohesion. Compared to Carron's first proposal [5], this model was less parameterized and the sub-dimensions of cohesion were clearly specified. However, interaction and communication and sacrifices were not clearly defined or easy to generalize, as Carron's and Spink's formulation was tailored to a fitness and exercise sample. The Conceptual Framework of Team Building was subsequently replaced by a more generalist proposal, namely the Conceptual Framework for Examining Sport Teams.

\section{Conceptual framework for examining sport teams}

In 1998, Carron and Hausenblas [6] proposed a new model focused on higher-order themes only. The model starts with member attributes and group environments as input exogenous variables. The model then illustrates how these two variables have direct effects on group structure, which in turn is shown to have a direct effect on group cohesion. Next, the model shows a direct effect from group cohesion to group processes, which in turn is shown to have direct effects on two outcomes, namely group products and individual products. From a broad perspective, this model was a significant leap forward as it provided a platform to advance research on the relationship between $\mathrm{CO}$, group structure, and group processes. Notwithstanding, to date, most studies based of this model have been on the effects of group structure changes on $\mathrm{CO}$ rather than on the relationship among various team processes [31, 32].

In contrast to TDT, the Conceptual Framework for Examining Sport Teams focuses on groups, and purports a linear view of group dynamics. Moreover, this model remains substantially broad as group processes and its underpinning sub-themes were not discussed or defined. Without welldefined themes, a theoretical nomological network linking "means and ends" cannot be tested, and thus alternative equivalent and non-equivalent models cannot be advanced [99, 159]. Furthermore, without discussing sub-themes, the unique factorial contributions of higher-order themes cannot be determined, and thus parsimonious models cannot be evolved [46, 160]. On these two grounds, stemming from Carron's and associates work, Filho et al. [33] proposed an integrated framework of team dynamics based on defined themes and sub-themes, namely the Integrated Framework of Team Dynamics in Sports.

\section{Integrated framework of team dynamics in sports}

The Integrated Framework of Team Dynamics in Sports differs from Carron and Hausenblas' [6] proposal in at least two ways. First, it shifts the emphasis from groups to teams [33]. Second, $\mathrm{CO}$ was set as an exogenous rather than endogenous variable, and its putative direct and indirect effects on TMM, $\mathrm{CE}$, and team performance were empirically tested. Explicitly, the following proposed nomological network was put to proof: CO-TMM-CE-TO. The statistical modelling revealed that CO predicted both TMM and CE beliefs. In turn, TMM and $\mathrm{CE}$ were found to be positively related and to predict team performance. Together, Filho et al. [33] findings lend support to the notion that team dynamics is not a linear process, as indicated by the observed correlational effect between TMM and CE. Furthermore, CO, TMM, and CE were found to represent unique non-overlapping factors, thus corroborating a parsimonious view of team dynamics.

The Integrated Framework of Team Dynamics in Sports was derived from Carron's previous proposals and used the factorial definitions of $\mathrm{CO}$ and $\mathrm{CE}$ described by Carron et al. [68] and Short et al. [109], respectively. Despite its contribution on how various team processes could be "integrated" in a statistical fashion, this model is not congruent with the notion that TMM is underpinned by shared and complementary mental models. Moreover, and perhaps more importantly, the model by Filho et al. [33] did not consider the important role of $\mathrm{CD}$ in team dynamics. As noted above, there is evidence that TMM is a formative indicator of $\mathrm{CD}$ and, more generally, teammates must coordinate their actions to perform optimally in team settings.

The theory proposed therein focuses on teams rather than groups, purports that team dynamics is not a linear process, and sets $\mathrm{CO}$ as an endogenous variable. Unlike earlier proposals, I propose that shared and complementary mental models are reflective indicators of TMM, and add CD to the theoretical matrix. Moreover, I put forth an ontological and nomological basis for the study of team dynamics in teams. Similar to how theory development proceeds across domains [1], TDT is the reshaping of previous models, with the demarcation of novel assumptions and propositions.

\section{Theoretical ontogenesis and nomological network}

Epistemology has taught us that theories stand on assumptions that require justification and lead to propositions [161]. TDT stands on two assumptions that lead to two central propositions. The first assumption establishes the origin, or ontogenesis, of the theory. The second assumption relies on a sub-set of "if" conditions that lead to "then" conclusions. By relying on both an ontological and nomological assumption, I establish a meta-stable theoretical space where alternative models can be tested (nomology) but where boundaries (ontogenis) are clear. In TDT, changes to the nomological network linking CO-TMM-CD-CE-TO can be proposed and tested, but the ontogenesis is clearly defined. 


\section{Ontological assumption}

Ontogenesis refers to the origination and development of an organism. TDT is put forth as an ontogenic theory to be tested and developed with the intent to aid researchers and practitioners interested in understanding and working with teams. The ontological assumption of TDT is that teams have a beginning and end.

\section{Every team has a starting point $\left(t_{0}\right)$ and an end point ( $\left.t \square\right)$}

To theorize, one must establish $t_{0}$ in order to create a nomological network where the theory can originate. In other words, every theory needs an ontogenesis or "ground zero". In human life, fertilization is $t_{0}$. In cosmology, the Big Bang is $t_{0}$. To explain continental drift, geologists established a given $t_{0}$ wherein all continents were clustered together into a supercontinent known as Pangea. Popper [1] and other metatheorists $[43,162,163]$ remind us that causality or inferred causality (e.g., via mediation analysis; dynamic causal modelling in the brain) needs time to occur or we cannot discuss input-output relations; or anteceding, mediating and moderating, and outcome factors within a nomological network. All of this is relevant because TDT focuses on teams. When individuals come together to establish a team for the first time $\left(t_{0}\right)$, imagining no previous interaction among the individuals, they do so because they are united towards common interdependent goals. That is the beginning of a team by definition and thus a sound origin for a theory on teams.

After $t_{0}$, teams will develop unique dynamics until reaching an end, or termination point $(t \square)$. Over their life cycle, individuals show different ontogenic developments. Different people will die sooner or later, and for different reasons. The same applies to teams. Teams will show distinct trajectory dynamics and termination may come sooner or later, depending on the individuals on the team, the team as a whole, or the broader context. "I" attributes (e.g., new teammates), "we" processes (e.g., new leadership with new goals), and the "context" at large (e.g., termination of a program due to financial resources), or perhaps an interaction of all three of these factors, may contribute to ending the life cycle of a team.

\section{Ontological proposition}

It is the strength of interdependent shared task and social goals that bring and keep individuals together as a team. Therefore, $\mathrm{CO}$ is the first process to form in teams. CO allows for the development of other team processes, which mutually influence one another, and together influence TO.
I theorize that team dynamics starts with CO (Fig. 4). There is consensus that a group of individuals only becomes a team when task or social goals are established [164-168]. This rationale also holds true for "multi-teams" (i.e., a macro-team formed by different teams), which can only be established through shared goals. For instance, in emergency situations, police, paramedics, and firefighters come together and remain united (i.e., cohesion) because of a shared goal [169]. After $t_{0}$, other team processes will develop and mutually influence one another, much like different organs in the human body develop over time and interact with one another after fecundation. This concept resonates with the notion of reciprocal determinism proposed by Bandura [4] and the idea of many-to-many basis relationship coined by Cacioppo and Berntson [170, 171]. Specifically, team processes are thought to hold multiple relations with one another (manyto-many basis relationship; e.g., CO is linked to TMM and $\mathrm{CE}$ ), and influence and are influenced by one another (i.e., reciprocal determinism; e.g., TMM influences CE which in turn influences TMM).

The life cycle of a team will continue until all interactive energy in the system is dissipated for one reason or another. After termination, a new influx of bonding energy in the form of shared task or social goals is needed to establish a new $t_{0}$. The reciprocal linkage established among team processes and team outcomes will vary within and between teams, as is often the case with nested data sets [172]. Over time, these relationships will change in magnitude and direction [173], akin to the empirical evidence that team dynamics change over time [174]. In turn, these time-bounded changes can establish different statistical geometries among CO-TMM-CD-CE-TO (Fig. 5). Similar to how a radar model is defined, these geometries can be estimated by "connecting the dots" among CO-TMM-CD-CE-TO through lines

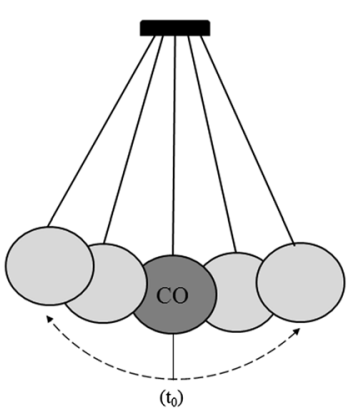

Fig. 4 Cohesion (CO) is the first team process to emerge, as a group of individuals only becomes a team after they establish communal interdependent goals. $\mathrm{CO}$ sets the team dynamics system into motion. After $t_{0}$, all team processes and outcomes, represented by the light gray circles, mutually interact and influence one another, similar to a pendulum. This motion continues until all interactive energy in the system is dissipated, which signifies the termination of the team. After termination, a new influx of bonding energy in the form of shared task or social goals is needed to establish a new team 
TEAM 'A'

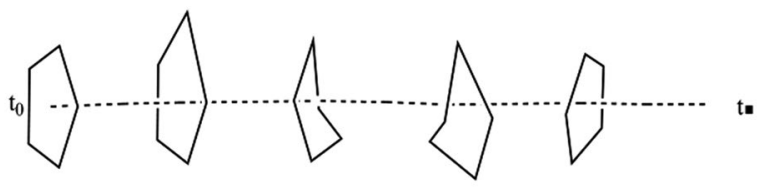

TEAM 'B'

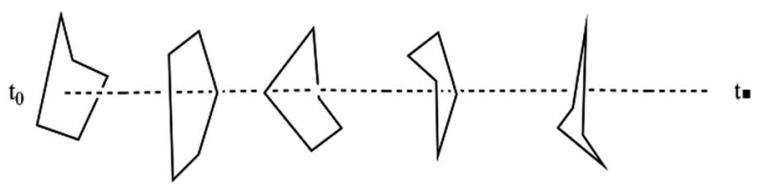

TEAM 'C'

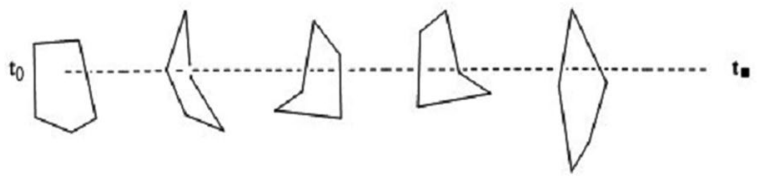

Fig. 5 The systemic linkage among team processes and outcomes differs by team over time, From team ontogenesis $\left(t_{0}\right)$ to termination $(\boldsymbol{a})$. Team 'a', Team 'b', and Team 'c' are examples of how team dynamics change over time. The different geometries established by the linkages among Cohesion, Team Mental Models, Coordination, Collective Efficacy, and Team Outcomes can be used to profile team resilience

scaled to represent the standardized statistical coefficients observed among team processes and TO [175]. It is proposed that these statistical geometries might represent a measure of team resilience, as resilience in complex systems is often assessed by small-world networks $[175,176]$. Initial breakdowns resulting from hardship can affect any, or multiple, team process at first, and may eventually cascade like a domino effect to the entire nomological network [177]. More resilient teams will bounce back from hardship and maintain the links among its various team processes. Changes over time may also create upward and downward spiral cycles (i.e., deviation amplifying feedback loops) among the COTMM-CD-CE-TO nomological network.

\section{Nomological assumption}

In the proposed nomological network CO, TMM, CD, and $\mathrm{CE}$ are inputs and/or throughputs, and TO is the output. Congruent with stepwise recommendations to test input-output relations in psychology $[99,178]$, a parsimonious theory of team dynamics will only be possible if the "if-then" assumption below is satisfied:

1. If all inputs are correlated yet conceptually unique; and

2. if all inputs correlate with the proposed output;

3. then an integrated parsimonious model can be proposed.
Therefore, TDT stands on the following nomological assumption:

The inputs and throughputs-CO, TMM, CD, and $\mathrm{CE}$ - are considered distinct latent constructs, meaning they show discriminant validity and there is no singularity (i.e., perfect correlation) or multicollinearity (i.e., strong correlation; $r \geq .80$ ) among them. These inputs and throughputs co-vary and influence, either directly or indirectly, the output TO.

The aforementioned "if-then" clause substantiating TDT's nomological assumption is at the core of logic [179]. Logic is flexible and serves as a foundation of nomological propositions wherein the matricing of inputs and throughputs is used to predict an output, such as in the case of TDT.

\section{Nomological proposition}

Complex phenomena, such as team dynamics, allow for multiple solutions and explanations [99, 159]. Such is the case with language, chemistry, music theory, and team dynamics, to name a few. For example, in language words can be combined in unlimited ways; reactions can be modeled through several pathways in chemistry; and musical notes can be arranged endlessly. Notwithstanding, it remains important to formulate a proposition thought to be the "best fit" to serve as the basis (null model) to inform further empirical testing of alternative models [98, 99]. That is, in principle there should be a more functional (best-fit) solution for a language discourse, chemical reaction, musical arrangement, and theory of team dynamics. As such, the following nomological proposition, as depicted in Fig. 6, is put forth:

$\mathrm{CO}$ will initially foster the development of TMM, which in turn is the basis for CD. CE beliefs will develop simultaneously with TMM and CD; that is, the higher the accuracy and quality of the TMM the higher the teams' $\mathrm{CE}$ and $\mathrm{CD}$ will be and vice-versa. Together, these team processes will influence, via direct or indirect means, TO.

The nomological proposition above is an attempt to reflect much of what has been discussed thus far. CO is established first in teams. Subsequently, the other team processes emerge and these processes influence one another and TO. These team processes represent parsimonious, unique factorial contributions to the study of "we" and "us" phenomenon related to TO. Finally, it is important to note that any serious attempt to discuss team dynamics should consider alternative models. 


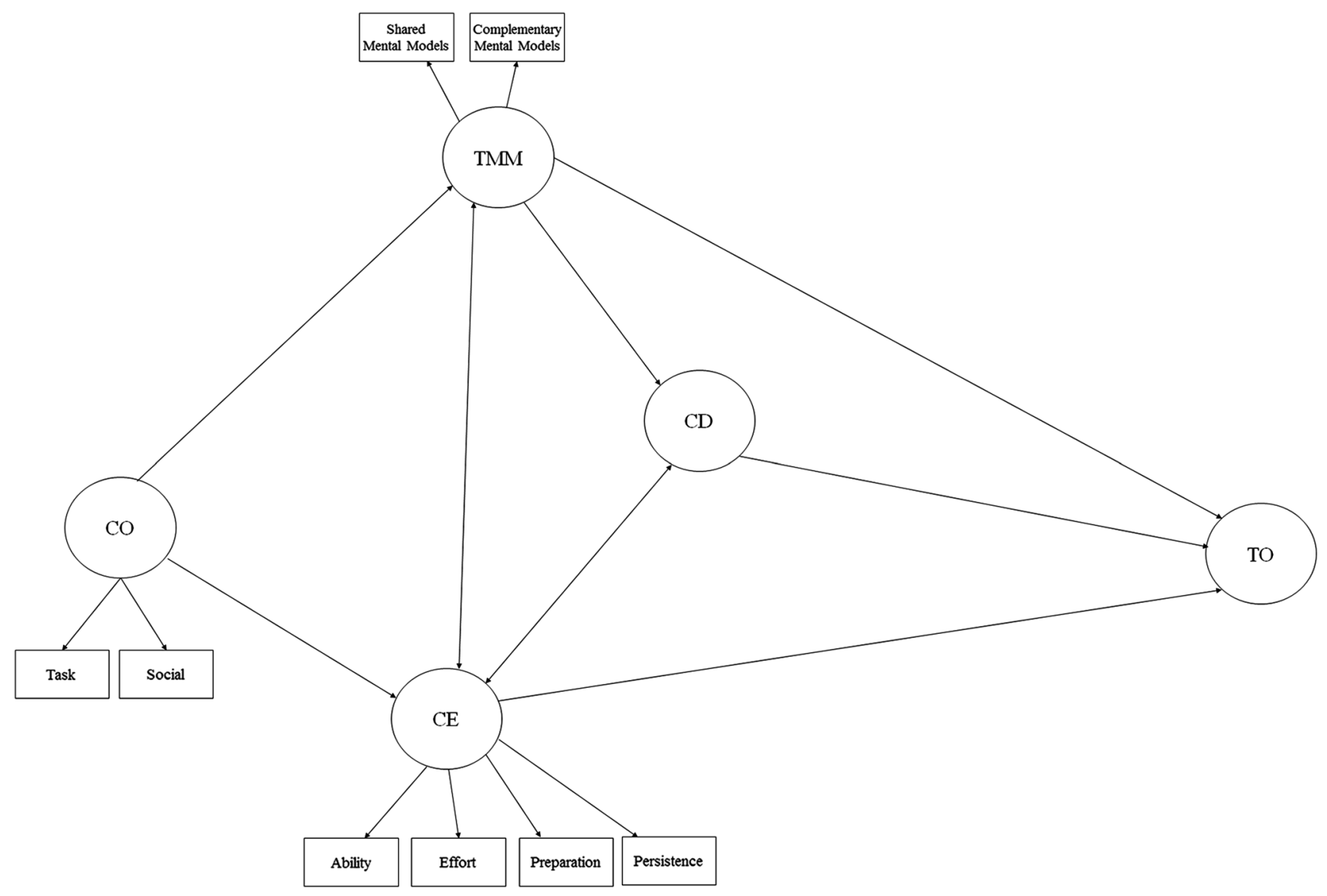

Fig. 6 Generative proposed nomological network. CO leads to the development of TMM and (CE. TMM leads to CD, which co-varies with CE. All team processes impact, via direct or indirect means, TO.
$C O$ Cohesion, TMM Team Mental Models, CE Collective Efficacy, $C D$ Coordination, $T O$ Team Outcomes

\section{Applying the theory}

TDT carries applied implications related to team development, the enhancement of team functioning, and the profiling of team resilience.

\section{Team development}

In light of TDT's ontological proposition, to create a team from scratch (in the case that individuals in the team have never met before; i.e., zero acquaintance relationship) practitioners should start by establishing high-quality goals to foster CO. To create a "new team", even if the members of the team are all the same, new team task and social goals must also be established. Shared task and social goals turn a group of individuals into a team and influence the development of other team processes. Strong task and social bonds will facilitate the development (in quantity and quality) of shared and complementary thoughts, feelings, and behavioral patterns. Strong $\mathrm{CO}$ also allows for confidence in the team as a whole to 


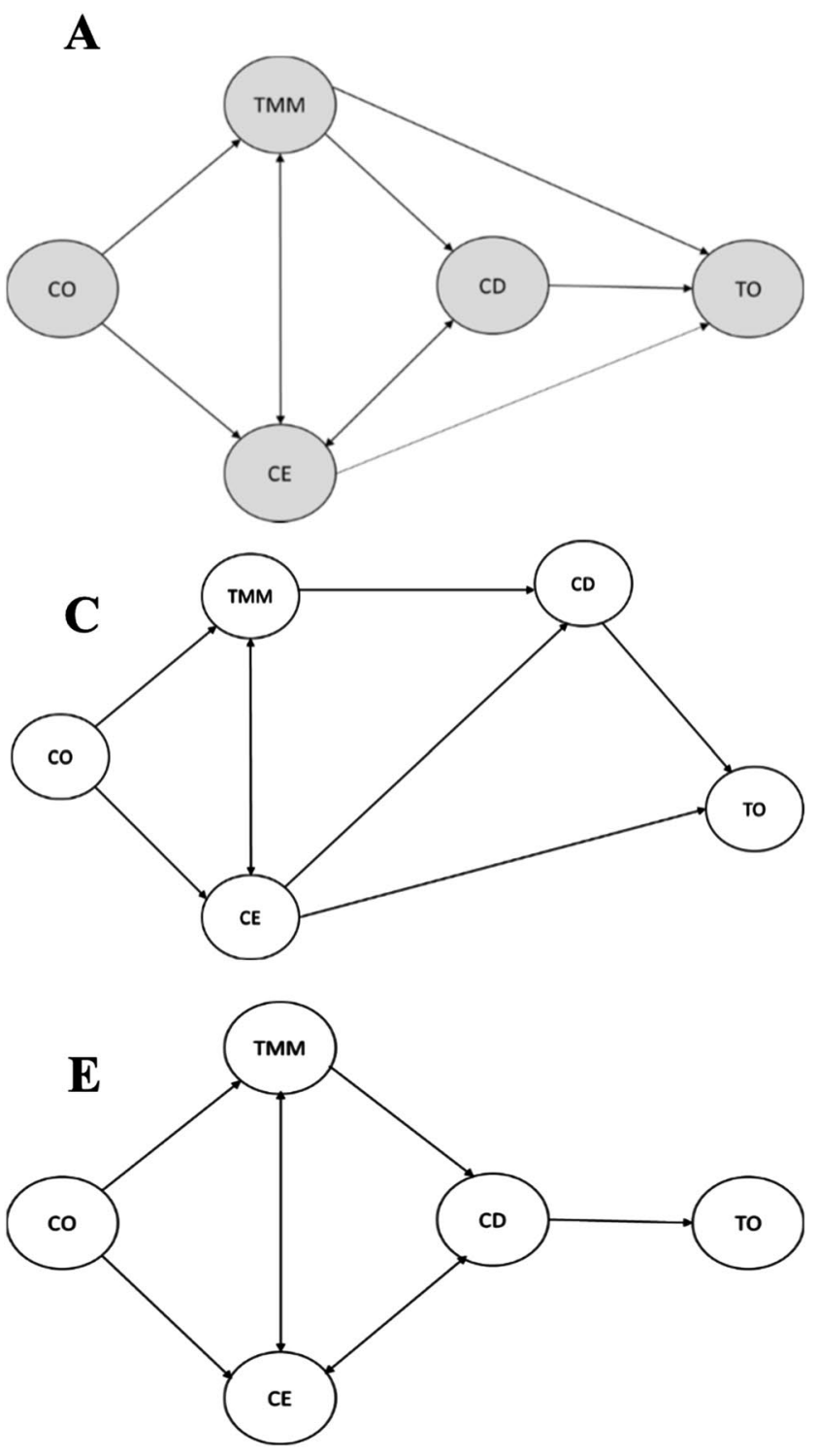

Fig. 7 TDT offers a class of models on the linkage among team processes and outcomes. The proposed nomological network is shown in shaded gray (a). Over-identified $(d f>0)$ alternative equivalent $(\mathbf{b})$ and non-equivalent models $(\mathbf{c}-\mathbf{f})$ are also presented. Permutation of the

emerge. Reciprocally, the more team members know about their shared and complementary strengths and weaknesses, the more likely they will trust themselves and each other and strengthen their mental models; and vice-versa. From there, space-time-action synchrony (i.e., CD) is likely to be enhanced and optimal performance is more likely to occur. That is, after a team is created through the establishment of task and social goals all team processes interact.

\section{Team functioning}

In light of TDT's nomological proposition, team functioning relates to the dynamic linkages among CO-TMM-CD-CE-TO.
B
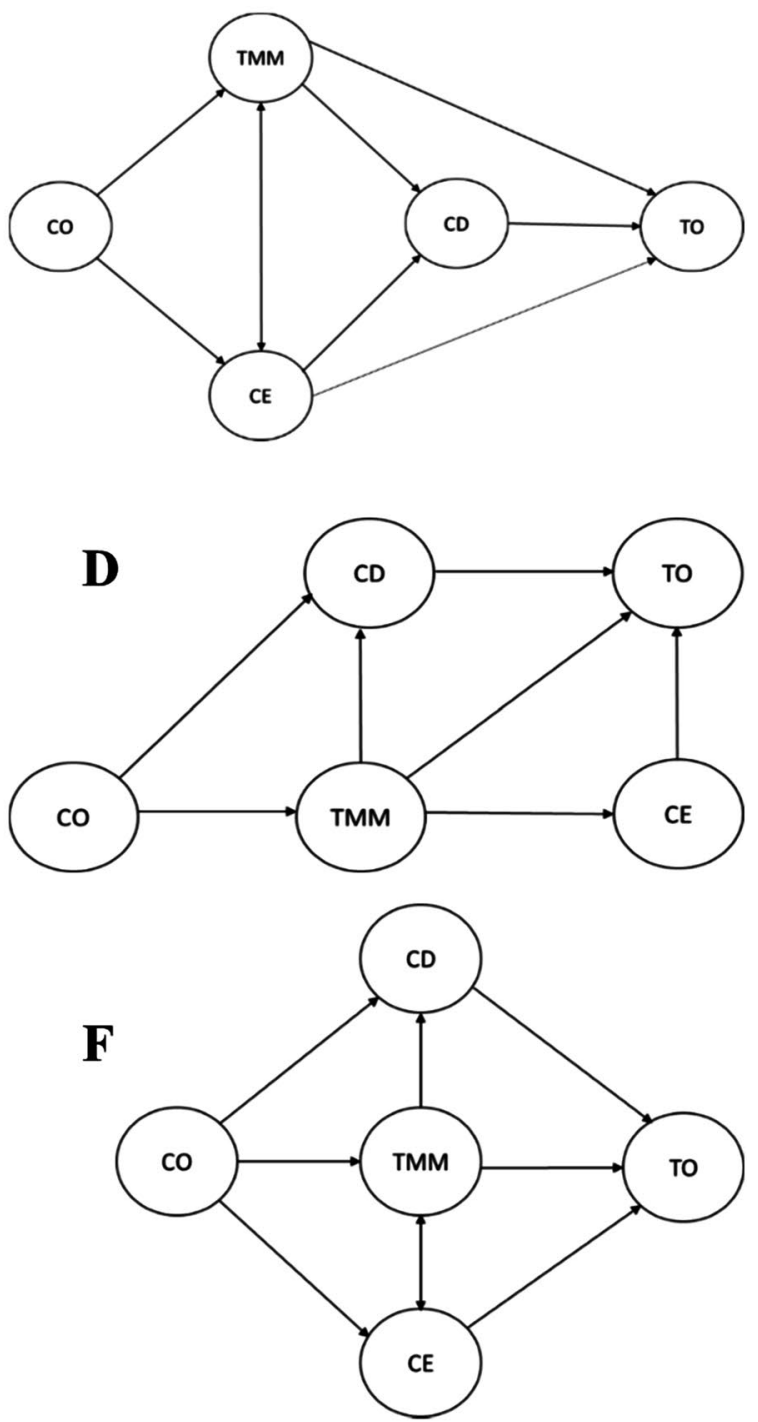

five higher-order themes proposed in TDT allows for 120 alternative models that might be more or less statistically accurate depending on the team, the individuals on the team, and the context in consideration

To develop high-functioning teams able to perform to their potential, it is crucial that practitioners understand the unique sources of CO, TMM, and CE, as well as the intrinsic bond between TMM and CD. Henceforth, practitioners should design interventions simultaneously targeting team processes and outcomes.

To enhance $\mathrm{CO}$, well-defined task and social goals are condition sine qua non [41]. Teams whereby every member has clear roles will perform better. Teams in which there are opportunities to interact socially and where fairness prevails will experience better outcomes. The composition of teams merits consideration as well. Homogeneous teams may outperform heterogeneous teams in simpler 
Panel A

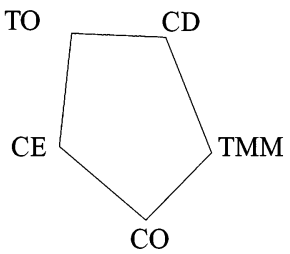

Panel C

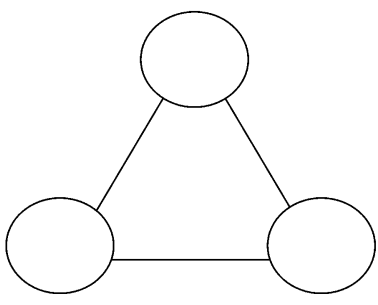

Panel B

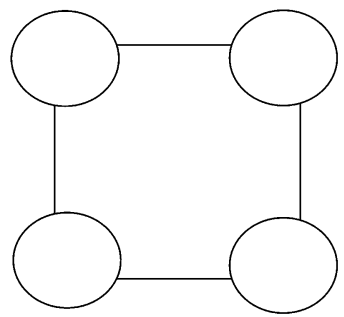

Panel D

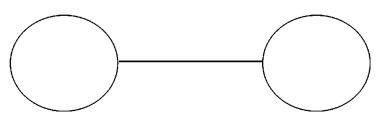

Fig. 8 Schematic representation on how TDT's nomological network can be evaluated in full (a) or in parts. A nomological network involving four variables (b) can be permuted in 120 different ways. Input-throughput-output relations among any three variables (c) can be proposed in 60 different ways. The directional bonds $(\rightarrow, \leftarrow, \leftrightarrow)$ between any two variables (d) can be examined through 20 different means

and short-term tasks, but heterogeneous teams may afford better TO in the long run. Maintaining an ideal team size will influence $\mathrm{CO}$ by preventing social loafing [181]. Too many team members can lead to social loafing, whereas too few team members make it difficult to assign unique roles to different members and gather the expertise needed to accomplish complex team tasks. To prevent groupthink (i.e., when team members tend to agree and make lessthan-optimum decisions in order to maintain high levels of cohesiveness at the expense of team performance), a potential side effect of high $\mathrm{CO}$, a culture of open communication should be fostered. Positive task and social conflict may help to dissolve cliques within teams, ultimately enhancing other team processes and TO [182].

To enhance TMM and CD, practitioners should develop different types of knowledge within a team. To be at the "right place, at the right time, doing the right thing", team members should know "who is doing what, why, where, when, and how". Shared and complementary descriptive, micro-tactical and macro-strategic, situational, temporal, and procedural mental models can be trained through different means. Teammates should be aware of other team members' individual traits, the team strategy, characteristics of the task at hand, and contextual constraints at large [90]. Teammates should also learn how to communicate effectively, engage in cross-training and role playing, deliberate about micro-tactics and macro-strategies, develop set-pieces and non-verbal signals, prepare contingency plans, perform video-analysis of their own and their opponents' strengths and weaknesses, and provide constructive feedback to one another [25, 183].

To enhance CE, practitioners should be mindful of the importance of recruiting "good fit" members to a team [184]. If the team task is complex and requires technical expertise, then the most skilled individuals possible should be recruited, as confidence across levels of analysis depends on ability. However, if the team task requires more effort than technical dexterity, recruiting "team players" might be better than recruiting "star players", as effort has been shown to predict efficacy beliefs. CE also comes from previous accomplishments but only objective accounts of success are not enough. Thus, practitioners should be aware that outcomes depend on processes, and thereby should avoid over-emphasizing an ego climate wherein winning is everything [185]. Instead, practitioners should promote a climate wherein preparation, effort, and persistence are valued and rewarded.

Above all, high-performing teams depend on various interdependent processes. To enhance team functioning, practitioners should view team dynamics in a systemic fashion by concurrently promoting the development of $\mathrm{CO}$, TMM, CD, and CE. These team processes are linked and bounded to reciprocal determinism, and thus improvement in any of them will likely simultaneously positively influence other team processes and TO. As the saying goes, "a chain is only as strong as its weakest links" and thus every link in a systemic view of team dynamics must be strengthened if teams are to reach and sustain optimal functioning. A systemic view of team dynamics may also allow for tracking team resilience through a topological analysis of TDT's nomological network.

\section{Team resilience}

TDT's nomological network carries implications to the assessment of resilience in teams. The Oxford dictionary defines resilience as "the ability of a substance or object to spring back into shape; elasticity" [186]. In team psychology, resilience carries an analogous meaning, denoting the ability of teams to adapt and recover from major biopsycho-social stressors [187, 188]. Conceptually, resilience is thought to reflect an "umbrella construct", insofar that resilient teams possess multiple well-developed team processes [189, 190]. To resist and bounce back from chaos, teams also rely on cohesiveness, shared and complementary schemas, and efficacy beliefs.

TDT reflects a systemic view of team dynamics wherein various team processes are interconnected. As such, I propose that algebraic random graphs created by the linkage among various team processes may serve as a diagnostic index of team resilience, much like radar maps are used to 
profile mental skills in individual psychology. Analyzing the networks created by the CO-TMM-CD-CE-TO linkage transcends the analysis of single team processes and emphasizes the "umbrella resilience construct" within an integrated nomological view of team dynamics. Importantly, a single definitive resilience map is unlikely to emerge, as different teams should show idiosyncratic inter-process linkages. Again, TDT purports a generative nomological model, whereby a vast repertoire of descriptive models can be derived to represent the realities of unique teams formed by unique individuals and bounded to singular contextual constraints. Rather than utilizing a "one-size fits all" approach by trying to summarize team resilience to a certain recipe, practitioners should embrace the complex nature of everchanging nomological networks [191].

Using algebraic topology to represent team resilience allows practitioners to observe the configuration (and reconfiguration) of the linkage among team processes across time [192-194]. It is therefore possible to observe how teams bounce back from "change events", such as losing streaks, coaching turnover, intra- and inter-team conflicts, burnout and myriad other bio-psycho-social stressors. By noting the temporal variation of "team resilience maps" practitioners may prevent decrements in team development and functioning. If the goal is not to enhance team functioning but rather "break teams apart", such as in the case of disrupting terror cells, the reverse of this logic applies. In effect, this rationale echoes a call to apply network science across domains by using random graphs and small-world network maps to monitor and eventually prevent epidemics, crime outbreaks, and power outages [177]. If practitioners notice that the relationship between two team processes is faulty (local failure) and may cascade to other processes (contagion effects), then applied measures can be advanced before negative global network effects (collapse) occur. These applied utterances, as well as the various tenets of TDT, need further research, as discussed next.

\section{Ways forward}

Thus far, I have proposed answers to "the demarcation problem" that TDT and all theoretical frameworks must face. Next, I do the exact opposite by outlining theoretical, methodological, and applied questions to challenge TDT, as science has a better chance to advance swiftly if scholars try not to prove but rather to falsify their own theorizing [1].

\section{Theoretical inquiry}

Researchers can first ask questions of scope. Testing the moderating effects of individual (e.g., age, gender, experience) and contextual factors (e.g., industry, culture) offers numerous avenues for future research. For instance, to stretch TDT's boundaries scholars can consider individual outputs (e.g., performance indicators) as outcome variables. Multilevel structural equation modelling and hierarchical linear modelling can be used to derive estimates of how individual outputs vary by teams. With the inclusion of individual outputs, the team processes proposed in TDT would represent level-2 factors. By extension of this logic, the influence of level-3 contextual factors on team processes can also be modeled. Noteworthy, the influence of level-2 team processes on level-1 individuals' cognitive, affective, and behavioral states and patterns also warrants exploration.

Scholars can expand TDT's tenets by proposing (and testing) additional themes to the theoretical mix. I encourage efforts on this front, particularly studies that can relate leadership to team processes and outcomes, while maintaining a parsimonious view of team dynamics. There are myriad different accounts of leadership and testing the effects of these variations on TDT's nomological network may yield fruitful insights on the psychology of high- and low-performing teams. The inclusion or exclusion of sub-themes to the team processes described in TDT is also worthy of research, notably studies on the reflective sub-themes of CE. It is known that $\mathrm{CE}$ is context-dependent, and the sub-themes outlined here might not apply across the board. Testing different TO might also yield insight about the compound predictive validity that various team processes carry over different criterion variables (e.g., objective performance; subjective performance; team satisfaction).

Questions can also be raised about the theoretical roots of TDT. I subscribed to previous frameworks in Sport, Exercise and Performance Psychology. Other models originating from different bodies of literature exist, such as industrial psychology and ecological dynamics [19, 194], and should be considered in terms of its theoretical roots, descriptive and explanatory features, and parsimonious and applied value. Overall, the juxtaposition of other theoretical streams to the study of team dynamics is welcomed. Theorists are therefore encouraged to engage in "explanatory pluralism" by applying different analytical outlooks to TDT's theoretical roots. For instance, relating TDT to meta-theories that have been used to explain human and group behavior at large, such as evolution and game theory, is a potential way forward.

Theorists may propose a new ontogenesis to TDT to expand its relevance to the study of groups rather than teams only. Nomologically, alternative models to the inputthroughput-output relations proposed herein can be tested in full or in parts, as alluded to previously (see Fig. 8c-f). Moreover, the statistical fit of TDT's null nomological network can be tested against data sets gathered from diverse working teams. Testing parts of TDT's nomological network includes examining the "bonds" between any two variables. Testing "bridges" (mediation relations) and "reciprocal linkages" over time (every variable can be both a cause and an 
effect) among three or more variables may also offer scholars an array of research questions.

\section{Methodological approaches}

TDT should undergo testing using different methodologies. There is consensus that the study of team processes should be analyzed via different qualitative and quantitative techniques and designs [195, 196]. Mixed method designs and multi-modal intakes might be particularly fruitful in revealing the mechanisms that allow for the development and optimal functioning of working teams. The development and refinement of psychometric tools to assess the reflective sub-themes discussed in TDT is also warranted. For instance, it is likely that instruments developed in different countries will show different sub-themes. Psychometric tools are especially needed to measure TMM, wherein terminological confusion has led to indistinct operational definitions and, consequently, unclear measurement models. Again, constrained multi-level models could be used to control and test for the influence of individual characteristics (e.g., gender) and contextual factors (e.g., Division-1 and Division-2 sport teams) on team dynamics. Longitudinal growth and cross-lagged modelling could be employed to test the notion that the linkage among team processes and outcomes varies over time. Longitudinal modelling can also be used to test whether different topographical maps, as formed by the linkages among team processes and outcomes, can indeed be used to profile and monitor team resilience.

Other curve-fit estimations involving specific team processes and outcomes, as well as TDT's nomological network as a whole, should also be explored. For instance, it is plausible that the CO-CE relationship is not linear but curvilinear, akin to the "too much of a good thing effect" described in the applied psychology literature. Too much CO can lead to groupthink and excessive $\mathrm{CE}$ can lead to complacency. The study of how TO spirals influence team processes and vice-versa can also be examined through non-linear statistics. For instance, dynamic causal modelling and Bayesian statistics might be particularly effective in creating alternative non-linear estimates of the linkage among team processes and outcomes.

TDT's propositions must also sustain the proof of social neuroscientific methods. Studies on hyperbrains/hyperminds are needed in team contexts. If latent team processes are valid, neuroscientific means should be able to capture neural markers of "we" processes, such as CO, TMM, CD, and CE [90]. For example, if TMM exists in the natural world, research, using neuro-psycho-physiological means, should be able to detect shared and complementary neural activity among teammates. Multi-brain studies may also advance understanding of the putative mirror neuron network and the mentalizing network, particularly their structural and functional links to the abstract latent notions of CO, TMM, and CE.
Neuro-psycho-physiological monitoring is warranted to study CD in teams, as the synchronization of bio-psychosocial responses has been shown to underpin coordinated joint action [197, 198]. Moderation research can examine whether inter-brains CD depends on the individuals (e.g., high-skill vs. low-skill) and teams involved (e.g., homogeneous vs. heterogeneous), the task (e.g., diachronic vs. interactive tasks), and the context (e.g., high pressure vs. low pressure). Applied intervention studies are also needed to test the directionality of input-output relations discussed in TDT.

\section{Applied studies}

Randomized control trials are appropriate to exam TDT's ontological proposition. Manipulating the quality and type of goal-setting strategies among zero-acquaintance individuals assigned to a group task may reveal how task and social cohesiveness levels influence the development of other team processes. Experimental manipulations are also suitable to examine TDT's nomological proposition. For instance, interventions addressing the extent and quality of shared and complementary mental models can assess the validity of the putative relationship between TMM and CD in working teams. Experimental studies comparing the effects of systemic interventions (on all team processes) with target interventions (on a specific team process) can examine the assumption that all processes are interdependent, and quantify the magnitude and direction of these interdependencies. Interventions targeting individuals on the team (e.g., psychological skills training), as well as the experimental manipulations of contextual variables (e.g., comparing novel vs. routine situations), are also appropriate next stages for research.

In certain contexts (e.g., school classes, company departments, and sport clubs), teams are already assembled and random assignment is not possible. In such cases, quasiexperimental studies are warranted. Quasi-experimental studies inevitably carry historicity confounders but represent a more realistic platform to test interventions aimed at enhancing team functioning in real-life situations. That said, multi-site studies are recommended to increase statistical power and provide replication evidence of research findings. Eventually, if a substantial body of research emerges, meta-analytical reviews should be carried out to summarize research findings and provide guidelines for best practices in the development and enhancement of team dynamics.

\section{Concluding summary}

The overarching goal herein was to propose an integrated, explanatory, and systemic theory of team dynamics. I first emphasized that a theory of team dynamics should focus on 
the team-level of analysis but also account for multilayered effects arising from individual members' characteristics and contextual constraints (Fig. 1). Next I highlighted the importance of well-defined and parsimonious constructs (Fig. 2), as ill-defined and overlapping constructs preclude the development of a coherent and testable nomological network. I then noted how previous models have informed the development of TDT (Fig. 3). I advanced an ontological proposition for the theory by remarking that $\mathrm{CO}$ is the first team process to emerge in a team because, imagining no previous interaction among individuals (i.e., zero-acquaintance condition), people come together and remain united (i.e., cohesion) to accomplish shared task and social goals. Noteworthy, I highlighted that after the "birth" of a team all team processes interact greatly like a pendulum (Fig. 4), and I suggested that the statistical geometries defined by these interactions can be used to study team resilience (Fig. 5). I also advanced a nomological network linking CO, TMM, CD, CE, and TO (Fig. 6). I asserted that from this general conceptualization numerous alternative (equivalent and non-equivalent) models can be proposed and empirically tested in different working teams, formed by unique individuals, and embedded in singular contexts (see Figs. 7, 8). Lastly, I discussed TDT's degrees of falsifiability by making an effort to challenge my own theorizing and identifying specific pathways for future research. Altogether, my hope is that TDT's goal will be achieved by stimulating research and provoking scholarly debate towards a parsimonious yet integrated, explanatory and systemic view of team dynamics.

\section{Compliance with ethical standards}

Conflict of interest The author declares he has no conflict of interest.

Ethical approval This article does not contain any studies with human participants performed by any of the authors.

Informed consent For this type of study formal consent is not required.

Open Access This article is distributed under the terms of the Creative Commons Attribution 4.0 International License (http://creativeco mmons.org/licenses/by/4.0/), which permits unrestricted use, distribution, and reproduction in any medium, provided you give appropriate credit to the original author(s) and the source, provide a link to the Creative Commons license, and indicate if changes were made.

\section{References}

1. Popper K (2005) The logic of scientific discovery. Routledge, New York

2. Bandura A (1978) The self system in reciprocal determinism. Am Psychol 33:344-358. https://doi.org/10.1037/0003066X.33.4.344

3. Bandura A (1983) Temporal dynamics and decomposition of reciprocal determinism. Psychol Rev 90:166-170
4. Bandura A (1997) Self-efficacy: the exercise of control. W. H. Freeman, New York

5. Carron AV (1982) Cohesiveness in sport groups: Interpretations and considerations. J Sport Psychol 4:123-138. https:// doi.org/10.1123/jsp.4.2.123

6. Carron AV, Hausenblas HA (1998) Group dynamics in sport, 2nd edn. Fitness Information Technology, Morgantown

7. Carron AV, Spink KS (1993) Team building in an exercise setting. Sport Psychol 7:8-18. https://doi.org/10.1123/tsp.7.1.8

8. Carron AV, Spink KS, Prapavessis H (1997) Team building and cohesiveness in the sport and exercise setting: Use of indirect interventions. J Appl Sport Psychol 9:61-72. https://doi. org/10.1080/10413209708415384

9. Gershgoren L, Basevitch I, Filho E, Gershgoren A, Brill YS, Schinke RJ, Tenenbaum G (2016) Expertise in soccer teams: a thematic inquiry into the role of shared mental models within team chemistry. Psychol Sport Exerc 24:128-139. https://doi. org/10.1016/j.psychsport.2015.12.002

10. Johnson TE, Lee Y, Lee M, OConnor DL, Khalil MK, Huang X (2007) Measuring sharedness of team-related knowledge: design and validation of a shared mental model instrument. Hum Resour Dev Int 10:437-454. https://doi. org/10.1080/13678860701723802

11. Klimoski R, Mohammed S (1994) Team mental model: construct or metaphor? J Manag 20:403-437. https://doi. org/10.1177/014920639402000206

12. Lim BC, Klein KJ (2006) Team mental models and team performance: a field study of the effects of team mental model similarity and accuracy. J Organ Behav 27:403-418. https:// doi.org/10.1002/job.387

13. Mathieu JE, Heffner TS, Goodwin GF, Salas E, Cannon-Bowers J (2000) The influence of shared mental models on team process and performance. J Appl Psychol 85:273-283

14. Mohammed S, Ferzandi L, Hamilton K (2010) Metaphor no more: a 15-year review of the team mental model construct. J Manag 36:876-910. https://doi.org/10.1177/0149206309356804

15. Mohammed S, Klimoski R, Rentsch JR (2000) The measurement of team mental models: we have no shared schema. Org Res Methods 3:123-165. https://doi.org/10.1177/109442810032001

16. Rouse WB, Cannon-Bowers JA, Salas E (1992) The role of mental models in team performance in complex systems. IEEE Trans Syst Man Cyberne 22:1296-1308. https://doi. org/10.1109/21.199457

17. Salas E, Cooke NJ, Rosen MA (2008) On teams, teamwork, and team performance: discoveries and developments. Hum Factors 50:540-547. https://doi.org/10.1518/001872008X288457

18. Ward P, Eccles DW (2006) A commentary on "team cognition and expert teams: emerging insights into performance for exceptional teams. Int J Sport Exerc Psychol 4:463-483. https ://doi.org/10.1080/1612197X.2006.9671808

19. Araújo D, Bourbousson J (2016) Theoretical perspectives on interpersonal coordination for team behavior. Int Coorn Perf Soc Syst 20:126-139

20. Bourbousson J, Poizat G, Saury J, Sève C (2010) Team coordination in basketball: description of the cognitive connections among teammates. J Appl Sport Psychol 22:150-166. https:// doi.org/10.1080/10413201003664657

21. Cienki A (2015) Insights into coordination, collaboration, and cooperation from the behavioral and cognitive sciences: a commentary. Interact Stud 16:553-560. https://doi.org/10.1075/ is.16.3.09cie

22. Eccles DW, Tenenbaum G (2004) Why an expert team is more than a team of experts: a social-cognitive conceptualization of team coordination and communication in sport. J Sport Exerc Psy 26:542-560. https://doi.org/10.1123/jsep.26.4.542 
23. Eccles DW, Tenenbaum G (2007) A social-cognitive perspective on team functioning in sport. In: Tenenbaum G, Eklund RC (eds) Handbook of sport psychology, 3rd edn. Wiley, Hoboken, pp 264-283

24. Eccles D (2016) Team coordination. In: Schinke RJ, McGannon KR, Smith B (eds) Psychology international handbook of sport psychology. Routledge, New York

25. Eccles DW, Tran KB (2012) Getting them on the same page: Strategies for enhancing coordination and communication in sports teams. J Sport Psychol Action 3:30-40. https://doi. org/10.1080/21520704.2011.649229

26. Fiore SM, Salas E, Cuevas HM, Bowers CA (2003) Distributed coordination space: toward a theory of distributed team process and performance. Theor Issues Ergo Sci 4:340-364. https://doi. org/10.1080/1463922021000049971

27. Gorman JC (2014) Team coordination and dynamics: two central issues. Curr Dir Psychol Sci 23:355-360. https://doi. org/10.1177/0963721414545215

28. Jennings NR (1993) Commitments and conventions: the foundation of coordination in multi-agent systems. Knowl Eng Rev 8:223-250. https://doi.org/10.1017/S0269888900000205

29. Richards D (2001) Coordination and shared mental models. Am J Polit Sci 45:259-276

30. Stout RJ, Cannon-Bowers JA, Salas E, Milanovich DM (1999) Planning, shared mental models, and coordinated performance: an empirical link is established. J Hum Fact Ergon Soc 41:61-71. https://doi.org/10.1518/001872099779577273

31. Bruner M, Eys M, Beauchamp M, Côté J (2013) Examining the origins of team building in sport: a citation network and genealogical approach. Group Dyn-Theor Res 17:30-42. https://doi. org/10.1037/a0030114

32. Collins J, Durand-Bush N (2015) Frameworks of team processes in sport: a critical review with implications for practitioners. Int J Hum Move Sports Sci 3:46-59. https://doi.org/10.13189 /saj.2015.030304

33. Filho E, Tenenbaum G, Yang Y (2015) Cohesion, team mental models, and collective efficacy: towards an integrated framework of team dynamics in sport. J Sport Sci 33:641-653. https://doi. org/10.1080/02640414.2014.957714

34. Kleinert J, Ohlert J, Carron B, Eys M, Feltz D, Harwood C, ... Sulprizio M (2012) Group dynamics in sports: an overview and recommendations on diagnostic and intervention. Sport Psychol 26:412-434. https://doi.org/10.1123/tsp.26.3.412

35. Liu B, Zang Z (2010) The mediating effects of team efficacy on the relationship between a transactive memory system and team performance. Soc Behav Personal 38:865-869. https://doi. org/10.2224/sbp.2010.38.7.865

36. Martin LJ, Carron AV, Burke SM (2009) Team building interventions in sport: a meta-analysis. Sport Exerc Psych Rev 5:3-18

37. Mathieu J, Maynard MT, Rapp T, Gilson L (2008) Team effectiveness 1997-2007: a review of recent advancements and a glimpse into the future. J Manag 34:410-476. https://doi. org/10.1177/0149206308316061

38. Salas S, Sims DE, Burke CS (2005) Is there a "big five" in teamwork? Small Gr Res 36:555-599. https://doi.org/10.1177/10464 96405277134

39. Williamson K, Cox R (2014) Distributed cognition in sports teams: explaining successful and expert performance. Educ Philos Theory 46:640-654. https://doi.org/10.1080/00131 857.2013.779215

40. Watkins MJ (1984) Models as toothbrushes. Behav Brain Sci 7:86. https://doi.org/10.1017/S0140525X00026303

41. Carron AV, Eys MA (2012) Group dynamics in sport, 4th edn. Fitness Information Technology, Morgantown

42. Filho E, Tenenbaum G (2015) Sports psychology. Oxford bibliographies. Oxford University Press, Oxford
43. Chomsky N (1965) Aspects of the theory of syntax. MIT Press, Cambridge

44. Dryer MS (2006) Descriptive theories, explanatory theories, and basic linguistic theory. Trend Lin S 167:207-234

45. Goldstein DG, Gigerenzer G (2011) The beauty of simple models: themes in recognition heuristic research. Judgm Decis Mak 6:392-395

46. Von Bertalanffy L (1969) General system theory: foundations, development, applications (Revised Edition). George Braziller, New York

47. Kim M, Hannafin M, Bryan L (2007) Technology-enhanced inquiry tools in science education: an emerging pedagogical framework for classroom practice. Sci Educ 96:1010-1030. https://doi.org/10.1002/sce

48. Dongfang Y, Fengyou W, Sixi Z, Huazhong H, Yunjie W (2014) Earth ecosystem theory: i theoretical system. Meteor Environ Res 5:11-12

49. Müller F (1997) State-of-the-art in ecosystem theory. Ecol Model 100:135-161. https://doi.org/10.1016/S0304 -3800(97)00156-7

50. Grossman R, Friedman SB, Kalra S (2017) Teamwork processes and emergent states. In: Salas. E, Rico R, Passmore J (eds) The psychology of team working and collaborative processes. Wiley Blackwell, Hoboken

51. Kozlowski SWJ, Klein KJ (2000) A multilevel approach to theory and research in organizations: Contextual, temporal, and emergent processes. In: Klein KJ, Kozlowski SWJ (eds) Multilevel theory, research and methods in organizations: Foundations, extensions, and new directions. Jossey-Bass, San Francisco, pp 3-90

52. Marks MA, Mathieu JE, Zaccaro SJ (2001) A temporally based framework and taxonomy of team processes. Acad Manag Rev 26:356-376. https://doi.org/10.5465/AMR.2001.4845785

53. Mathieu JE, Tannenbaum SI, Salas E (1992) Influences of individual and situational characteristics on measures of training effectiveness. Acad Manag J 35:828-847. https://doi. org/10.2307/256317

54. Cling AD (2008) The epistemic regress problem. Philos Stud 140:401-421. https://doi.org/10.1007/s11098-007-9152-6

55. Northouse PG (2012) Leadership: theory and practice. Sage Publications, Thousands Oaks

56. Burke PJ (1971) Task and social-emotional leadership role performance. Sociometry 34:22-40. https://doi.org/10.2307/2786349

57. De Jong JP, Den Hartog DN (2007) How leaders influence employees' innovative behaviour. Euro J Innovation Manag 10:41-64. https://doi.org/10.1108/14601060710720546

58. Fransen K, Vanbeselaere N, De Cuyper B, Vande Broek G, Boen F (2014) The myth of the team captain as principal leader: extending the athlete leadership classification within sport teams. J Sport Sci 32:1389-1397. https://doi. org/10.1080/02640414.2014.891291

59. Filho E, Rettig J (2016) Intergroup conflict management strategies from a Nobel Peace Laureate: the case of Jose RamosHorta. Basic Appl Soc Psych 38:351-361

60. Collinson D (2014) Dichotomies, dialectics and dilemmas: new directions for critical leadership studies? Leadership 10:36-55. https://doi.org/10.1177/1742715013510807

61. Vanderslice VJ (1988) Separating leadership from leaders: An assessment of the effect of leader and follower roles in organizations. Hum Relat 41:677-696. https://doi.org/10.1177/00187 2678804100903

62. Arnold R, Fletcher D (2012) A research synthesis and taxonomic classification of the organizational stressors encountered by sport performers. J Sport Exerc Psys 34:397-429

63. Cotterill ST, Fransen K (2016) Athlete leadership in sport teams: current understanding and future directions. Int Rev 
Sport Exerc 9:116-133. https://doi.org/10.1080/17509 84X.2015.1124443

64. Pescosolido AT, Saavedra R (2012) Cohesion and sports teams: A Review. Small Gr Res 43:744-758. https://doi. org/10.1177/1046496412465020

65. Cashmore E (2002) Sport and exercise psychology: The key concepts. Routledge, New York

66. Festinger L, Schachter S, Back K (1950) Social pressures in informal groups: a study of human factors in housing. Stanford University Press, Stanford

67. Martin LJ, Paradis KF, Eys MA, Evans B (2013) Cohesion in sport: new directions for practitioners. J Sport Psychol Action 4:14-25. https://doi.org/10.1080/21520704.2012.702710

68. Carron AV, Widmeyer WN, Brawley LR (1985) The development of an instrument to assess cohesion in sport teams: The group environment questionnaire. J Sport Psychol 7:244-266. https:// doi.org/10.1123/jsp.7.3.244

69. Eys MA, Carron AV, Bray SR, Brawley LR (2007) Item wording and internal consistency of a measure of cohesion: The Group Environment Questionnaire. J Sport Exercise Psys 29:395-402. https://doi.org/10.1123/jsep.29.3.395

70. Glasser W (2010) Choice theory: a new psychology of personal freedom. HarperCollins Publishers, New York

71. Duarte A, Weissing FJ, Pen I, Keller L (2011) An evolutionary perspective on self-organized division of labor in social insects. Annu Rev Ecol Evol 42:91-110. https://doi.org/10.1146/annur ev-ecolsys-102710-145017

72. Scheel D, Packer C (1991) Group hunting behaviour of lions: a search for cooperation. Anim Behav 41:697-709. https://doi. org/10.1016/S0003-3472(05)80907-8

73. Carron AV, Brawley LR (2000) Cohesion conceptual and measurement issues. Small Gr Res 31:89-106. https://doi. org/10.1177/104649640003100105

74. Cooke NJ, Gorman JC, Myers CW, Duran JL (2013) Interactive team cognition. Cognitive Sci 37:255-285. https://doi. org/10.1111/cogs.12009

75. Filho E, Tenenbaum G (2012) Team mental models in sports: an overview. In: Schinke R (ed) Athletic insight's writings in sport psychology. Nova Science Publishers, Inc., Hauppauge

76. Filho E, Bertollo M, Tamburro G, Schinaia L, Chatel-Goldman J, di Fronso S, Robazza C, Comani S (2016) Hyperbrain features of team mental models within a juggling paradigm: a proof of concept. PeerJ. https://doi.org/10.7717/peerj.2457

77. Krioukov D, Kitsak M, Sinkovits RS, Rideout D, Meyer D, Boguná M (2012) Network cosmology. Nat Sci Rep 2:793. https ://doi.org/10.1038/srep00793

78. Likens AD, Amazeen PG, Stevens R, Galloway T, Gorman JC (2014) Neural signatures of team coordination are revealed by multifractal analysis. Soc Neurosci 9:219-234. https://doi. org/10.1080/17470919.2014.882861

79. Astolfi L, Toppi J, Borghini G, Vecchiato G, He EJ, Roy A, ... Babiloni F (2012) Cortical activity and functional hyperconnectivity by simultaneous EEG recordings from interacting couples of professional pilots. Paper presented at the IEEE Engineering in Medicine and Biology Society Annual Conference (pp. 47524755). https://doi.org/10.1109/EMBC.2012.6347029

80. Lindenberger U, Li SC, Gruber W, Müller V (2009) Brains swinging in concert: cortical phase synchronization while playing guitar. BMC Neurosci 10:1-12. https://doi. org/10.1186/1471-2202-10-22

81. Sänger J, Müller V, Lindenberger U (2012) Intra- and interbrain synchronization and network properties when playing guitar in duets. Front Hum Neurosci 6:1-19. https://doi.org/10.3389/ fnhum.2012.00312

82. Sänger J, Müller V, Lindenberger U (2013) Directionality in hyperbrain networks discriminates between leaders and followers in guitar duets. Front Hum Neurosci 7:1-14. https:// doi.org/10.3389/fnhum.2013.00234

83. Blickensderfer EL, Reynolds R, Salas E, Cannon-Bowers JA (2010) Shared expectations and implicit coordination in tennis doubles teams. J Appl Sport Psychol 22:486-499. https://doi. org/10.1080/10413200.2010.507497

84. Bourbousson J, Poizat G, Saury J, Sève C (2011) Description of dynamic shared knowledge: an exploratory study during a competitive team sports interaction. Ergonomics 54:120-138. https://doi.org/10.1080/00140139.2010.544763

85. Cannon-Bowers JA, Salas E (2001) Reflections on shared cognition. J Organ Behav 22:195-202. https://doi.org/10.1002/job.82

86. Filho E, Pierini D, Robazza C, Tenenbaum G, Bertollo M (2017) Shared mental models and intra-team psychophysiological patterns: a test of the juggling paradigm. J Sport Sci 35:112-123

87. Kirschner S, Tomasello M (2009) Joint drumming: social context facilitates synchronization in preschool children. J Exp Child Psychol 102:299-314. https://doi.org/10.1016/j.jecp.2008.07.005

88. Beniscelli V, Tenenbaum G, Schinke RJ, Torregrosa M (2014) Perceived distributed effort in team ball sports. J Sport Sci 32:710-721. https://doi.org/10.1080/02640414.2013.853131

89. Campo M, Sanchez X, Ferrand C, Rosnet E, Friesen A, Lane AM (2016) Interpersonal emotion regulation in team sport: mechanisms and reasons to regulate teammates' emotions examined. Int J Sport Exercise Psychol. https://doi.org/10.1080/16121 97X.2015.1114501

90. Filho E, Bertollo M, Robazza C, Comani S (2015) The juggling paradigm: a novel social neuroscience approach to identify neuropsychophysiological markers of team mental models. Front Psychol 5:1-6

91. Waller MJ, Gupta N, Giambatista RC (2004) Effects of adaptive behaviors and shared mental models on control crew performance. Manag Sci 50:1534-1544. https://doi.org/10.1287/ mnsc. 1040.0210

92. Lewis K (2004) Knowledge and performance in knowledge-worker teams: a longitudinal study of transactive memory systems. Manag Sci 50:1519-1533. https://doi.org/10.1287/mnsc.1040.0257

93. Yoo Y, Kanawattanachai P (2001) Developments of transactive memory systems and collective mind in virtual teams. Int J Org Anal 9:187-208. https://doi.org/10.1108/eb028933

94. Galantucci B (2005) An experimental study of the emergence of human communication systems. Cogn Sci 29:737-767

95. McNeill D (2008) Gesture and thought. The University of Chicago Press, Chicago

96. Shamir B, Zakay E, Breinin E, Popper M (1998) Correlates of charismatic leader behavior in military units: subordinates' attitudes, unit characteristics, and superiors' appraisals of leader performance. Acad Manag J 41:387-409. https://doi.org/10.2307/257080

97. Filho E, Gershgoren L, Basevitch I, Schinke R, Tenenbaum G, 2014 Peer leadership and shared mental models in a college volleyball team: a season long case study. J Clin Sport Psych 8:184-203

98. Hoyle RH (2011) Structural equation modeling for social and personality psychology. Sage Publications, Thousands Oaks

99. Kline RB (2011) Principles and practice of structural equation modeling, 3rd edn. The Guilford Press, New York

100. Bougon M, Weick K, Binkhorst D (1977) Cognition in organizations: an analysis of the Utrecht Jazz Orchestra. Admin Sci Quart 22:606-639

101. Bourbousson J, R'Kiouak M, Eccles DW (2015) The dynamics of team coordination: a social network analysis as a window to shared awareness. Eur J Work Organ Psys 24:742-760. https:// doi.org/10.1080/1359432X.2014.1001977

102. Eccles D (2010) The coordination of labour in sports teams. Int Rev Sport Exerc 3:154-170. https://doi.org/10.1080/17509 84X.2010.519400 
103. Sebanz N, Bekkering H, Knoblich G (2006) Joint action: bodies and minds moving together. Trends Cogn Sci 10:70-76. https://doi.org/10.1016/j.tics.2005.12.009

104. Stajkovic AD, Lee D, Nyberg AJ (2009) Collective efficacy, group potency, and group performance: meta-analyses of their relationships, and test of a mediation model. J Appl Psychol 94:814-828. https://doi.org/10.1037/a0015659

105. Maddux JE (1999) The collective construction of collective efficacy: comment on Paskevich, Brawley, Dorsch, and Widmeyer. Group Dyn-Theor Res 3:223-226. https://doi. org/10.1037/1089-2699.3.3.223

106. Feltz DL, Short SE, Sullivan PJ (2008) Self-efficacy in sport. Human Kinetics, Champaign

107. Feltz DL, Lirgg CD (2001) Self-efficacy beliefs of athletes, teams, and coaches. In: Singer RN, Hausenblas HA, Janelle CM (eds) Handbook of sport psychology, 2nd edn. Wiley, New York, pp 389-416

108. Myers ND, Feltz DL (2007) From self-efficacy to collective efficacy in sport: transitional methodological issues. In: Tenenbaum G, Eklund RC (eds) Handbook of sport psychology, 3rd edn. Wiley, New York, pp 799-819

109. Short SE, Sullivan P, Feltz DL (2005) Development and preliminary validation of the collective efficacy questionnaire for sports. Measur Phys Educ Exerc Sci 9:181-202. https://doi. org/10.1207/s15327841mpee0903_3

110. Bandura A (2001) Guide for constructing self-efficacy scales (Monograph). Stanford University, Stanford

111. Dithurbide L, Feltz DL (2012) Self and collective efficacy. In: Tenenbaum G, Eklund R, Kamata A (eds) Handbook of measurement in sport and exercise psychology. Human Kinetics, Champaign, pp 251-263

112. Greenlees IA, Graydon JK, Maynard IW (1999) The impact of collective efficacy beliefs on effort and persistence in a group task. J Sport Sci 17:151-158. https://doi.org/10.1080/02640 4199366253

113. Burton D, Raedeke TD (2008) Sport psychology for coaches. Human Kinetics, Champaign

114. Goddard RD, Hoy WK, Hoy AW (2004) Collective efficacy beliefs: theoretical developments, empirical evidence, and future directions. Educ Res 33:3-13. https://doi. org/10.3102/0013189X033003003

115. Salas E, Rico R, Passmore J (2017) The Wiley Blackwell handbook of the psychology of team working and collaborative processes. Wiley-Blackwell, Hoboken

116. Latham GP, Locke EA (2007) New developments in and directions for goal-setting research. Eur Psychol 12:290-300. https ://doi.org/10.1027/1016-9040.12.4.290

117. Locke EA, Latham GP (2006) New directions in goal-setting theory. Curr Dir Psychol Sci 15:265-268. https://doi.org/10.1 111/j.1467-8721.2006.00449.x

118. Weinberg RS (1995) Goal setting in sport and exercise: results, methodological issues and future directions for research. Rev Psicol Deport 4:115-125

119. Podsakoff PM, MacKenzie SB, Lee JY, Podsakoff NP (2003) Common method biases in behavioral research: a critical review of the literature and recommended remedies. J Appl Psychol 88:879-903. https://doi.org/10.1037/0021-9010. 88.5.879

120. Chelladurai $P$ (2007) Leadership in sports. In: Tenenbaum G, Eklund RC (eds) Handbook of sport psychology, 3rd edn. Wiley, Hoboken, pp 113-135

121. Hoegl M, Gemuenden HG (2001) Teamwork quality and the success of innovative projects: a theoretical concept and empirical evidence. Organ Sci 12:435-449. https://doi.org/10.1287/ orsc.12.4.435.10635
122. Carron AV, Colman MM, Wheeler J, Stevens D (2002) Cohesion and performance in sport: a meta-analysis. J Sport Exercise Psys 24:168-188. https://doi.org/10.1123/jsep.24.2.168

123. Evans CR, Dion KL (2012) Group cohesion and performance: a meta-analysis. Small Gr Res 43:690-701. https://doi. org/10.1177/1046496412468074

124. Filho E, Dobersek U, Gershgoren L, Becker B, Tenenbaum G (2014) The cohesion-performance relationship in sport: a 10-year retrospective meta-analysis. Sport Sci Health 10:165-177. https ://doi.org/10.1007/s11332-014-0188-7

125. Gully SM, Devine DJ, Whitney DJ (1995) A meta-analysis of cohesion and performance effects of level of analysis and task interdependence. Small Gr Res 26:497-520. https://doi. org/10.1177/1046496495264003

126. Cooke NJ, Kiekel PA, Helm EE (2001) Measuring team knowledge during skill acquisition of a complex task. Int J Cogn Ergonomics 5:297-315. https://doi.org/10.1207/S15327566IJCE0503_10

127. Gurtner A, Tschan F, Semmer NK, Nägele C (2007) Getting groups to develop good strategies: Effects of reflexivity interventions on team process, team performance, and shared mental models. Organ Behav Hum Dec 102:127-142. https://doi. org/10.1016/j.obhdp.2006.05.002

128. Johnson TE, Lee Y (2008) The relationship between shared mental models and task performance in an online team-based learning environment. Perfor Improv Q 21:97-112. https://doi. org/10.1002/piq.20033

129. Marks MA, Sabella MJ, Burke CS, Zaccaro SJ (2002) The impact of cross-training on team effectiveness. J Appl Psychol 87:3

130. Mathieu JE, Heffner TS, Goodwin GF, Cannon-Bowers JA, Salas E (2005) Scaling the quality of teammates' mental models: Equifinality and normative comparisons. J Organ Behav 26:37-56. https://doi.org/10.1002/job.296

131. Mohammed S, Dumville BC (2001) Team mental models in a team knowledge framework: Expanding theory and measurement across disciplinary boundaries. J Organ Behav 22:89-106. https ://doi.org/10.1002/job.86

132. Ren Y, Carley KM, Argote L (2006) The contingent effects of transactive memory: when is it more beneficial to know what others know? Manag Sci 52:671-682. https://doi.org/10.1287/ mnsc. 1050.0496

133. Rentsch JR, Klimoski RJ (2001) Why do 'great minds' think alike?' Antecedents of team member schema agreement. J Organ Behav 22:107-120. https://doi.org/10.1002/job.81

134. Tsai YH, Joe SW, Chen ML, Lin CP, Ma HC, Du JW (2016) Assessing team performance: Moderating roles of transactive memory, hypercompetition, and emotional regulation. Hum Perform 29:89-105. https://doi.org/10.1080/08959285.2016.1154059

135. Zhou Y, Wang E (2010) Shared mental models as moderators of team process-performance relationships. Soc Behav Personal38:433-444. https://doi.org/10.2224/sbp.2010.38.4.433

136. Feltz DL, Lirgg CD (1998) Perceived team and player efficacy in hockey. J Appl Psychol 83:557-564. https://doi. org/10.1037//0021-9010.83.4.557

137. Fransen K, Decroos S, Vanbeselaere N, Vande Broek G, De Cuyper B, Vanroy J, Boen F (2015) Is team confidence the key to success? The reciprocal relation between collective efficacy, team outcome confidence, and perceptions of team performance during soccer games. J Sport Sci 33:219-231. https://doi.org/10.1080/02640414.2014.942689

138. Fuster-Parra P, García-Mas A, Ponseti FJ, Leo FM (2015) Team performance and collective efficacy in the dynamic psychology of competitive team: a Bayesian network analysis. Hum Mov Sci 40:98-118. https://doi.org/10.1016/j.humov.2014.12.005

139. Myers ND, Paiement CA, Feltz DL (2007) Regressing team performance on collective efficacy: Considerations of temporal 
proximity and concordance. Measur Phys Edu Exerc Sci 11:124. https://doi.org/10.1080/10913670709337009

140. Myers ND, Feltz DL, Short SE (2004) Collective efficacy and team performance: a longitudinal study of collegiate football teams. Gr Dynam 8:126. https://doi. org/10.1037/1089-2699.8.2.126

141. Leo FM, González-Ponce I, Amado D, Pulido JJ, García-Calvo $\mathrm{T}$ (2016) An approach to group processes in female professional sport. Euro Hum Mov 36:57-74

142. Heuzé J, Sarrazin P, Masiero M, Raimbault N, Thomas J (2006) The relationships of perceived motivational climate to cohesion and collective efficacy in elite female teams. J Appl Sport Psychol 18:201-218. https://doi.org/10.1080/10413200600830273

143. Kozub S, McDonnell J (2000) Exploring the relationship between cohesion and collective efficacy in rugby teams. J Sport Behav 23:120

144. Leo FM, González-Ponce I, Sánchez-Miguel PA, Ivarsson A, García-Calvo T (2015) Role ambiguity, role conflict, team conflict, cohesion and collective efficacy in sport teams: a multilevel analysis. Psychol Sport Exerc 20:60-66. https://doi. org/10.1016/j.psychsport.2015.04.009

145. Leo FM, Sánchez-Miguel PA, Sánchez-Oliva D, Amado D, García-Calvo T (2012) Evolution of perceived cohesion and efficacy over the season and their relation to success expectations in soccer teams. J Hum Kinet 34:129-138. https://doi.org/10.2478/ v10078-012-0072-y

146. Paskevich DM, Brawley LR, Dorsch KD, Widmeyer WN (1999) Relationship between collective efficacy and team cohesion: conceptual and measurement issues. Group Dyn-Theor Res 3:210 222. https://doi.org/10.1037/1089-2699.3.3.210

147. Spink KS (1990) Group cohesion and collective efficacy of volleyball teams. J Sport Exerc Psys 12:301-311. https://doi. org/10.1123/jsep.12.3.301

148. Chou HW, Lin YH, Chou SB (2012) Team cognition, collective efficacy, and performance in strategic decision-making teams. Soc Behav Personal 40:381-394. https://doi.org/10.2224/ sbp.2012.40.3.381

149. Mathieu JE, Rapp TL, Maynard MT, Mangos PM (2009) Interactive effects of team and task shared mental models as related to air traffic controllers' collective efficacy and effectiveness. Hum Perform 23:22-40. https://doi.org/10.1080/0895928090 3400150

150. Peterson E, Mitchell TR, Thompson L, Burr R (2000) Collective efficacy and aspects of shared mental models as predictors of performance over time in work groups. Gr Process Inter 3:296-316. https://doi.org/10.1177/1368430200033005

151. Goldman AI (2012) Theory of mind. In: Margolis E, Samuels $\mathrm{R}$, Stich S (eds) Oxford handbook of philosophy and cognitive science. Oxford University Press, Oxford

152. Bandura A (1977) Social learning theory. General Learning Press, New York

153. Bandura A (1986) Social foundations of thought and action: a social cognitive theory. Prentice-Hall, Englewood Cliffs

154. Bressler SL, Kelso JS (2016) Coordination dynamics in cognitive neuroscience. Front Neurosci 10:1-7. https://doi.org/10.3389/ fnins.2016.00397

155. McGrath JE (1964) Social psychology: a brief introduction. Holt, Rinehart, and Winston, New York

156. Carron (1982) Cohesiveness in sport groups: Interpretations and considerations. J Sport Psychol 4:123-138. https://doi. org/10.1123/jsp.4.2.123

157. Carron AV, Brawley LR (2008) Group dynamics in sport and physical activity. In: Horn TS (ed) Advances in sport psychology, 3rd edn. Human Kinetics, Champaign, pp 213-238

158. Carron AV, Hausenblas HA, Eys MA (2005) Group dynamics in sport, 3rd edn. Fitness Information Technology, Morgantown
159. Hershberger SL (2006) The problem of equivalent structural models. In: Hancock GR, Mueller RO (eds) Structural equation modeling: a second course. Information Age Publishing, Charlotte, pp 13-41

160. Tenenbaum G, Filho E (2015) Measurement considerations in performance psychology. In: Raab M, Lobinger B, Hoffmann S, Pizzera A, Laborde S (eds) Performance psychology: Perception, action, cognition, and emotion. Elsevier, Philadelphia, pp 31-44

161. Sherman B, Harman G (2011) Knowledge and assumptions. Philos Stud 156:131-140

162. Boje DM, Haley UC, Saylors R (2016) Antenarratives of organizational change: The microstoria of Burger King's storytelling in space, time and strategic context. Hum Relat 69:392-418. https ://doi.org/10.1177/0018726715585812

163. Hawking S (1989) A brief history of time: from big bang to black holes. Bantam Books, London

164. Carron AV, Eys MA, Burke SM (2007) Team cohesion: nature, correlates, and development. In: Jowette S, Lavalle D (eds) Social psychology in sport. Human Kinetics, Champaign, pp 91-102

165. Ginnett RC (1993) Crews as groups: their formation and their leadership. Crew Res Manag, 71-98

166. Hackman JR, Wageman R (2005) A theory of team coaching. Acad Manag Rev 30:269-287. https://doi.org/10.5465/ AMR.2005.16387885

167. Kozlowski SWJ, Bell BS (2003) Work groups and teams in organizations. In Borman WC, Ilgen DR, Klimoski RJ (eds), Handbook of psychology: industrial and organizational psychology (vol. 12)

168. Weinberg RS, Gould D (2014) Foundations of sport and exercise psychology, 6th edn. Human Kinetics, Champaign

169. Power N (2018) Extreme teams: toward a greater understanding of multiagency teamwork during major emergencies and disasters. Am Psychol 73:478-490. https://doi.org/10.1037/amp00 00248

170. Cacioppo JT, Tassinary LG (1990) Inferring psychological significance from physiological signals. Am Psychol 45:16-28. https://doi.org/10.1037/0003-066X.45.1.16

171. Cacioppo JT, Tassinary LG, Berntson GG (2007) Psychophysiological science: interdisciplinary approaches to classic questions about the mind. In: Cacioppo JT, Tassinary LG, Berntson G (eds) Handbook of psychophysiology, 3rd edn. Cambridge University Press, New York, pp 1-24

172. Raudenbush SW, Bryk AS (2002) Hierarchical linear models, 2nd edn. Sage Publications, Thousand Oaks

173. Holland JN, DeAngelis DL (2009) Consumer-resource theory predicts dynamic transitions between outcomes of interspecific interactions. Ecol Lett 12:1357-1366. https://doi.org/10.111 1/j.1461-0248.2009.01390.x

174. Bourbousson J, Fortes-Bourbousson M (2016) Fluctuations of the experience of togetherness within the team over time: taskcohesion and shared understanding throughout a sporting regular season. Ergonomics 60:810-823. https://doi.org/10.1080/00140 139.2016.1229041

175. Godsil C, Royle GF (2013) Algebraic graph theory (vol 207). Springer, New York

176. Watts DJ, Strogatz SH (1998) Collective dynamics of 'small-world' networks. Nature 393:440-442. https://doi. org/10.1038/30918

177. Kong Z, Yeh EM (2010) Resilience to degree-dependent and cascading node failures in random geometric networks. IEEE Trans Inf Theory 56:5533-5546. https://doi.org/10.1109/ TIT.2010.2068910

178. Holmbeck GN (1997) Toward terminological, conceptual, and statistical clarity in the study of mediators and moderators: examples from the child-clinical and pediatric psychology literatures. J Consult Clin Psych 65:599-610 
179. Gabbay DM, Guenthner F (eds) (2014) Handbook of philosophical logic. Springer Netherlands, Houten

180. Ng AY, Jordan MI (2002) On discriminative vs. generative classifiers: a comparison of logistic regression and naive bayes. Adv Neural Inf Process Syst 2:841-848

181. Steiner ID (1972) Group process and productivity. Academic Press, New York

182. De Wit FR, Greer LL, Jehn KA (2012) The paradox of intragroup conflict: a meta-analysis. J Appl Psychol 97:360-390. https://doi. org/10.1037/a0024844

183. Cannon-Bowers JA, Salas E (1998) Team performance and training in complex environments: recent findings from applied research. Curr Direct Psychol Sci 7:83-87. https://doi. org/10.1111/1467-8721.ep10773005

184. Hesketh B, Griffin B (2016) Person-environment fit. The encyclopedia of adulthood and aging. 5:1-5

185. Duda JL (2013) The conceptual and empirical foundations of Empowering Coaching ${ }^{\mathrm{TM}}$ : Setting the stage for the PAPA project. Int J Sport Exerc Psychol 11:311-318. https://doi. org/10.1080/1612197X.2013.839414

186. Bonanno GA, Romero SA, Klein SI (2015) The temporal elements of psychological resilience: An integrative framework for the study of individuals, families, and communities. Psychol Inq 26:139-169. https://doi.org/10.1080/1047840X.2015.992677

187. Yukelson D, Weinberg R (2016) Team resiliency in sport: research to practice. In: Schinke RJ, McGannon KR, Smith B (eds) Routledge international handbook of sport psychology. Routledge, New York, pp 547-558

188. Decroos S, Lines RL, Morgan PB, Fletcher D, Sarkar M, Fransen K, Vande Broek G (2017) Development and validation of the characteristics of resilience in sports teams inventory. Sport Exerc Perform 6:158. https://doi.org/10.1037/spy0000089
189. Galli N (2016) Team resilience. In: Schinke RJ, McGannon KR, Smith B (eds) Routledge international handbook of sport psychology. Routledge, New York, pp 378-386

190. Mišić B, Sporns O (2016) From regions to connections and networks: new bridges between brain and behavior. Curr Opin Neurobiol 40:1-7. https://doi.org/10.1016/j.conb.2016.05.003

191. Carley KM (1997) Extracting team mental models through textual analysis. J Organ Behav 533-558. https://doi.org/10.1002/ (SICI) 1099-1379(199711)18:1\&\%23x002B;\%3C533::AIDJOB906\%3E3.0.CO;2-3

192. Katz N, Lazer D, Arrow H, Contractor N (2004) Network theory and small groups. Small Gr Res 35:307-332. https://doi. org/10.1177/1046496404264941

193. Khambhati A, Sizemore A, Betzel R, Basset D (2017) Modelling and interpreting network dynamics. BioRxiv 5:1-17

194. McEwan D, Beauchamp MR (2014) Teamwork in sport: a theoretical and integrative review. Int Rev Sport Exerc Psychol 7:229-250

195. Seifert L, Adé D, Saury J, Bourbousson J, Thouvarecq R (2016) Mix of phenomenological and behavioural data to explore interpersonal coordination in outdoor activities. Int Coordinat Perform Soc Syst 5:109

196. Wildman JL, Salas E, Scott CP (2014) Measuring cognition in teams: a cross-domain review. Hum Fact 56:911-941. https://doi. org/10.1177/0018720813515907

197. Kelso JS (2012) Multistability and metastability: understanding dynamic coordination in the brain. Philos T Roy Soc B 367:906918. https://doi.org/10.1098/rstb.2011.0351

198. Müller V, Lindenberger U (2011) Cardiac and respiratory patterns synchronize between persons during choir singing. PloS One 6:e24893. https://doi.org/10.1371/journal.pone.0024893 